\title{
RECOVERY OF YTTRIUM AND NEODYMIUM FROM COPPER PREGNANT LEACH SOLUTIONS BY SOLVENT EXTRACTION
}

by

\author{
Rebecca Copp
}

\author{
A Thesis Submitted to the Faculty of the \\ DEPARTMENT OF MINING AND GEOLOGICAL ENGINEERING
}

In Partial Fulfillment of the Requirements

For the Degree of

MASTER OF SCIENCE

WITH A MAJOR IN MINING, GEOLOGICAL AND GEOPHYSICAL ENGINEERING

In the Graduate College

THE UNIVERSITY OF ARIZONA 


\section{STATEMENT BY AUTHOR}

This thesis has been submitted in partial fulfillment of requirements for an advanced degree at the University of Arizona and is deposited in the University Library to be made available to borrowers under rules of the Library.

Brief quotations from this thesis are allowable without special permission, provided that an accurate acknowledgement of the source is made. Requests for permission for extended quotation from or reproduction of this manuscript in whole or in part may be granted by the head of the major department or the Dean of the Graduate College when in his or her judgment the proposed use of the material is in the interests of scholarship. In all other instances, however, permission must be obtained from the author.

SIGNED: Rebecca Copp

\section{APPROVAL BY THESIS DIRECTOR}

This thesis has been approved on the date shown below:

$\begin{array}{cc}\text { J. Brent Hiskey } & \text { January 6, 2016 } \\ \text { Professor of Mining \& Geological Engineering } & \text { Date }\end{array}$




\section{Table of Contents}

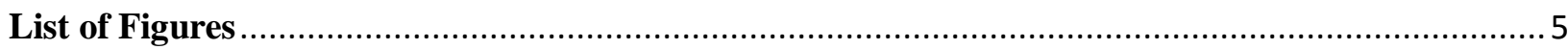

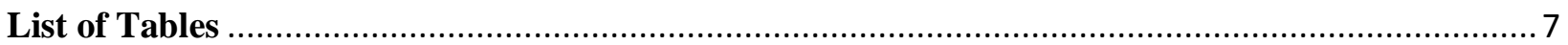

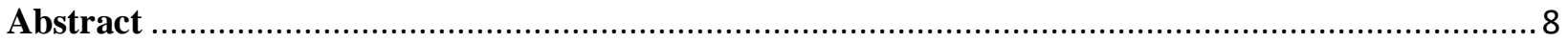

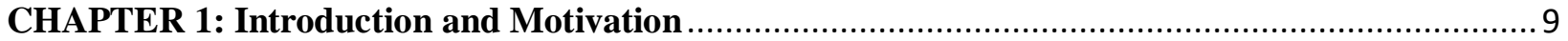

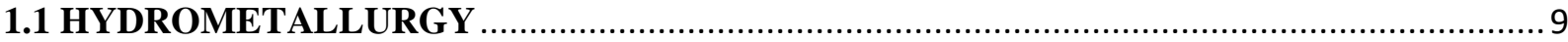

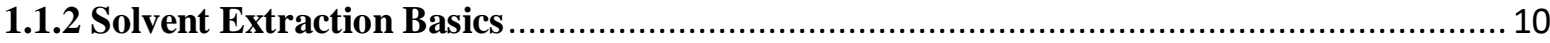

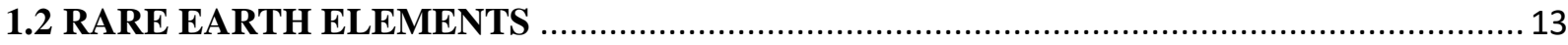

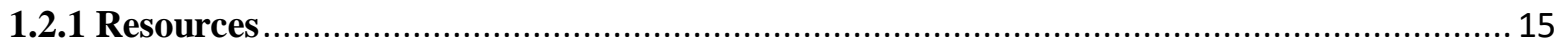

1.2.2 Recovery of Rare Earth Elements from Conventional Resources ................................. 20

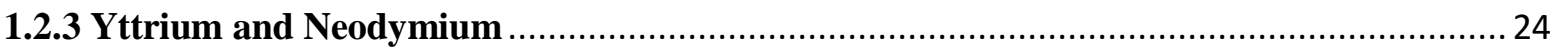

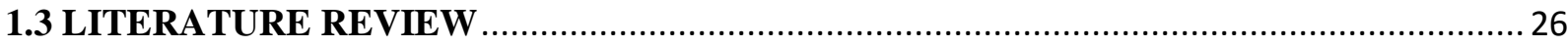

1.3.1 Extraction of Dissolved Metals from Copper PLS …............................................. 26

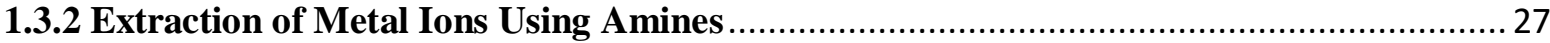

1.3.3 Extraction of Trivalent Rare Earths with Primene JM-T ........................................... 28

1.3.4 Extraction of Yttrium from Sulfate Solutions .......................................................... 29

1.4 RARE EARTHS IN COPPER PORPHYRY DEPOSITS ….............................................. 31

CHAPTER 2: Solutions, Extraction Mechanism, and Experimental Procedure ............................ 33

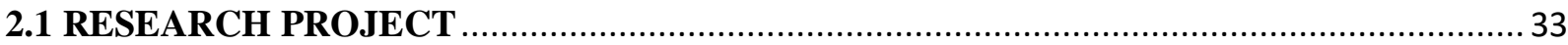

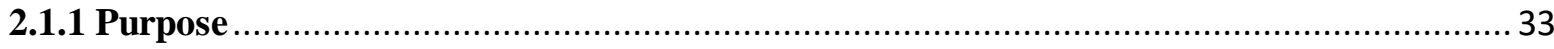

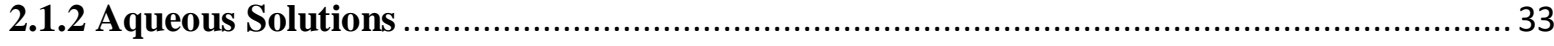

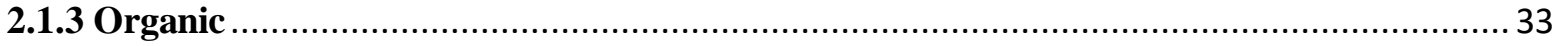

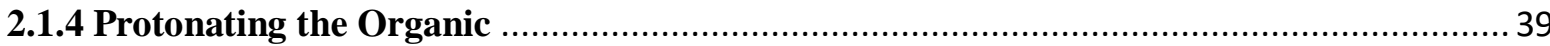

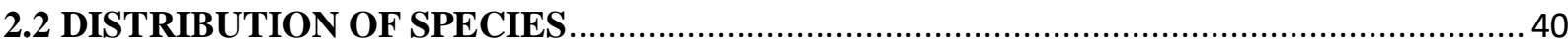

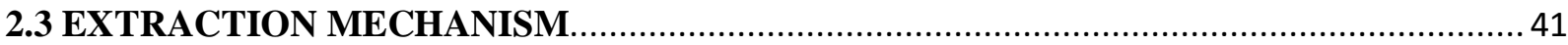

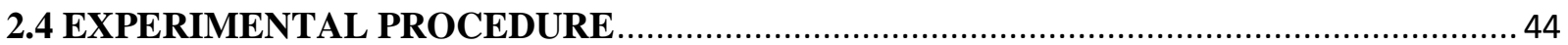

CHAPTER 3: Recovery of Yttrium and Neodymium from Synthetic Solutions ............................ 47

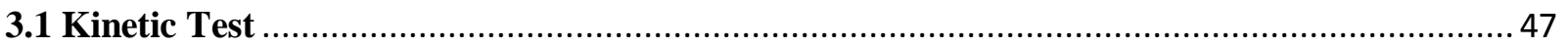

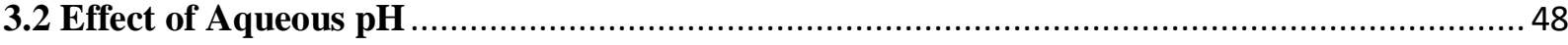

3.3 Effect of Aqueous Sulfate Concentration ........................................................................ 50

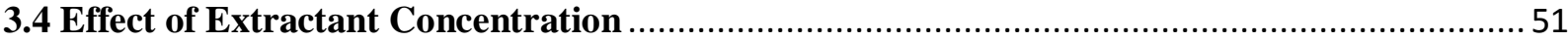

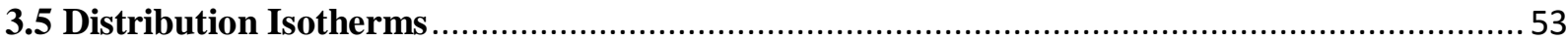


CHAPTER 4: Recovery of Yttrium and Neodymium from Copper PLS .................................. 58

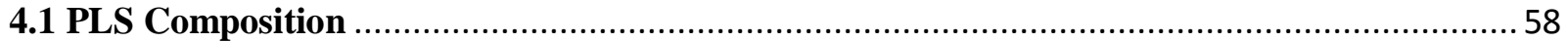

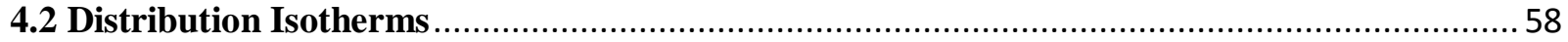

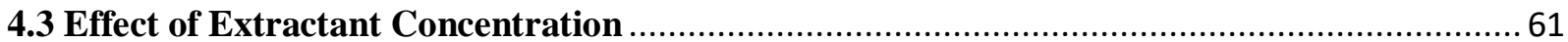

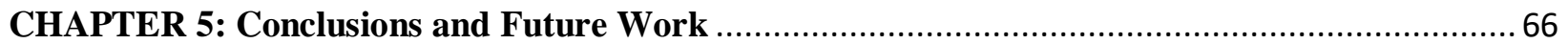

5.1 Conclusions

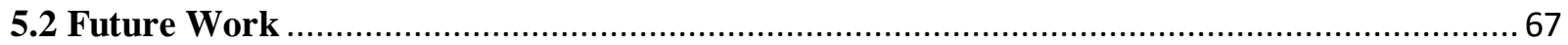

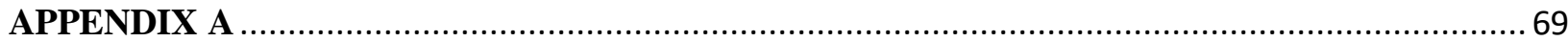

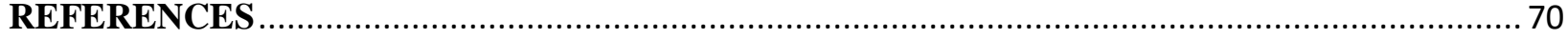




\section{List of Figures}

Figure 1.1: Solvent extraction process diagram..................................... 11

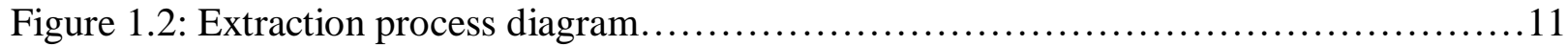

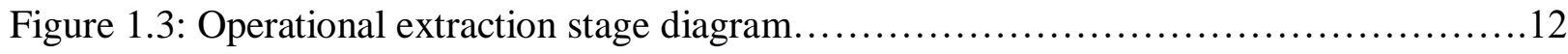

Figure 1.4: World rare earth production.............................................. 16

Figure 1.5: Crustal abundance of the rare earths................................... 19

Figure 1.6: Recovery of rare earth oxides from bastnasite ore $\ldots \ldots \ldots \ldots \ldots \ldots \ldots \ldots \ldots \ldots \ldots . .21$

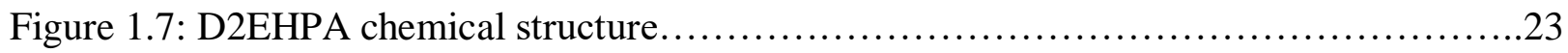

Figure 1.8: Molycorp's rare earth solvent extraction process............................23

Figure 1.9: Percent yttrium extraction as a function of $\mathrm{pH}$ for primary, secondary, tertiary, and

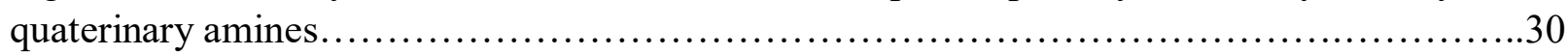

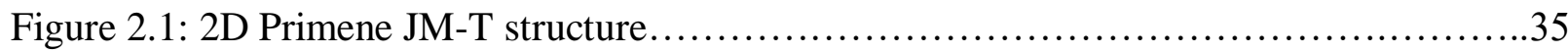

Figure 2.2: Effect of diluent type on percent extraction............................... 37

Figure 2.3: Distribution of species............................................ 41

Figure 3.1: Percent extraction of yttrium and neodymium from synthetic solutions as a function of $\mathrm{pH}$.

Figure 3.2: Percent extraction of yttrium from synthetic yttrium solution as a function of Primene JM-T concentration. .52

Figure 3.3: Distribution coefficient as a function of Primene JM-T concentration using synthetic

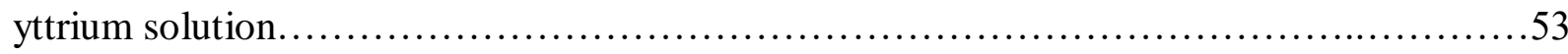

Figure 3.4 Distribution isotherm using synthetic yttrium solution......................54

Figure 3.5: High and low yttrium concentration distribution isotherm comparison using synthetic

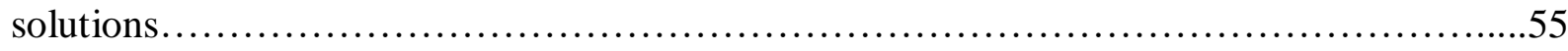

Figure 3.6: Distribution isotherm using synthetic neodymium solution...................56

Figure 3.7: Single contact vs. multiple contacts using synthetic yttrium solution..............57

Figure 4.1: Yttrium distribution isotherm using PLS ..............................60

Figure 4.2: Neodymium distribution isotherm using PLS ............................60

Figure 4.3: Percent extraction of yttrium as a function of Primene JM-T concentration using PLS. 
Figure 4.4: Distribution coefficient of yttrium as a function of Primene JM-T concentration using

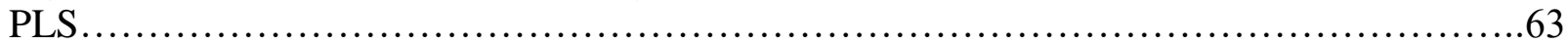

Figure 4.5: Percent extraction of neodymium as a function of Primene JM-T concentration using

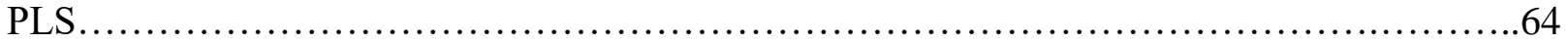

Figure 4.6: Distribution coefficient of neodymium as a function of Primene JM-T concentration

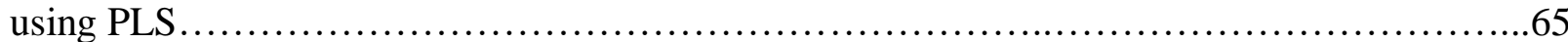




\section{List of Tables}

Table 1:1 Composition of Typical Rare Earth Bearing Minerals........................... 14

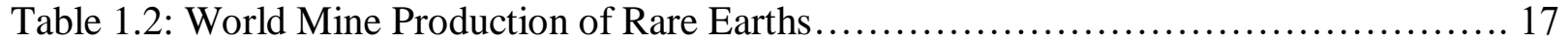

Table 1.3: Composition of Bastnasite Ores......................................... 18

Table 1.4: Crustal Abundance of the Rare Earths.......................................19

Table 1.5: Chemical Properties of Yttrium and Neodymium..............................24

Table 1.6: Rare Earth Element Composition of PLS in Arizona.............................31

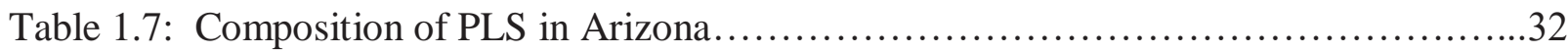

Table 2.1: Capacity of the Organic at Different Extractant Concentrations ....................38

Table 2.2: Formation Constants for Yttrium Sulfate Complexes..........................41

Table 3.1: Effect of Time on Yttrium Extraction from Synthetic Yttrium Solution ...........47

Table 3.2: Effect of $\mathrm{pH}$ on Yttrium and Neodymium Extraction from Synthetic Solutions.....49

Table 3.3: Effect of Sulfate Concentration on Yttrium Extraction from Synthetic Yttrium

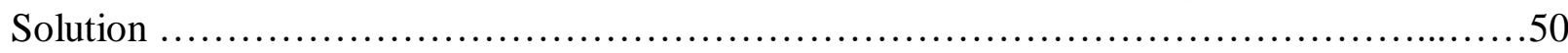

Table 3.4: Effect of Extractant Concentration on Yttrium Extraction from Synthetic Yttrium

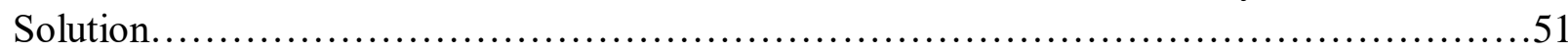

Table 3.5: Distribution Isotherm Results Using Synthetic Yttrium Solution...................54

Table 3.6: Distribution Isotherm Results Using Synthetic Neodymium Solution................56

Table 3.7: Distribution Isotherm with Multiple Contacts Using Synthetic Yttrium Solution.....57

Table 4.1: Yttrium and Neodymium Distribution Isotherms Using PLS ....................59

Table 4.2: Yttrium Effect of Extractant Concentration Using PLS ........................61

Table 4.3: Neodymium Effect of Extractant Concentration Using PLS....................63 


\begin{abstract}
The solvent extraction of yttrium and neodymium from copper pregnant leach solutions (PLS) using Primene JM-T, a primary aliphatic amine, has been studied. Effect of contact time, $\mathrm{pH}$, sulfate concentration, and extractant concentration were investigated using synthetic and actual PLS systems. Standard experimental conditions were 5 minute contact time, $\mathrm{pH} \sim 2.5,10 \%$ v/v Primene JM-T concentration, and 1:1 O:A phase ratio. Distribution isotherms were constructed for the pure systems and for actual copper leach solutions. Synthetic solutions contained $100 \mathrm{ppm}$ Y and $~ 75$ ppm Nd. Copper PLS contained $2.1 \mathrm{ppm} \mathrm{Nd}$ and $14.9 \mathrm{ppm} \mathrm{Y.} \mathrm{Results} \mathrm{showed} \mathrm{that}$ complete extraction of both yttrium and neodymium occurred within five minutes and at $\mathrm{pH}$ values greater than 1. It was also found that sulfate concentration does not inhibit extraction at any concentration. Additionally, the distribution isotherms created show that extraction for these metals can operationally take place in one stage from both synthetic solutions and copper leach solutions.
\end{abstract}




\section{CHAPTER 1: Introduction and Motivation}

\subsection{HYDROMETALLURGY}

Leaching, solvent extraction, and electrowinning are encompassed in the field of hydrometallurgy. Hydrometallurgy is a branch of extractive metallurgy by which metals can be recovered from crude ores, concentrates, or residual material. Aqueous chemistry is used to recover the desired metals. The purification of metals by aqueous chemistry began hundreds of years ago. Hydrometallurgy has roots dating back to the period of the alchemists (Habashi 2005). Today it is "well established as the principal method for extraction of many industrial metals" (Gupta and Mukherjee 1990). From the time of the alchemists through the present, many major advancements have occurred within the field of hydrometallurgy.

Notable advances in hydrometallurgy have occurred in all areas of the field. The discovery of aqua regia, a mixture of hydrochloric acid and nitric acid, which can be used to dissolve gold was one of the first major milestones achieved (Habashi 2005). Since then many developments have been made. For example, heap leaching was first used for the recovery of copper at Rio Tinto, Spain in the 1700s (Gupta and Mukherjee 1990), and the birth of modern hydrometallurgy can be attributed to the discovery of the cyanidation process for extracting gold and the Bayer process utilized in the production of alumina in the late 1800s (Habashi 2005). Other major innovations in hydrometallurgy have included the roast-leach-electrowinning process for zinc, dump and vat leaching, recovery of uranium, and the utilization of bacteria in leaching (Gupta and Mukherjee 1990). Many other new techniques and improvements have also been discovered over the years.

There have been a number of milestones in the processing of rare earth elements (REEs) specifically. In the 1900s ion exchange began being used for the separation of rare earths, and then solvent extraction became a notable method for the processing of rare earths and either replaced or was used in addition to ion exchange (Habashi 2005). This discovery that solvent extraction could be used for rare earths occurred in the 1930s (Gupta and Krishnamurthy 2005). Application of this technique for the separation of rare earths did not occur until a few years later when it was first observed that cerium (IV) could be separated from the trivalent rare earths by extraction with tributyl phosphate (TBP) (Gupta and Krishnamurthy 2005). The 
hydrometallurgical technique of solvent extraction has been used for rare earth processing since that time.

\subsubsection{Solvent Extraction Basics}

There are three main steps in the hydrometallurgical process. These steps are leaching, solution concentration and purification, and product recovery. There are multiple methods for solution concentration and purification. These methods include solvent extraction, ion exchange, and adsorption. This research focuses on solvent extraction. Solvent extraction includes extraction and stripping stages. This is all part of the hydrometallurgical process.

When solvent extraction is utilized, the first three steps in the process are leaching, extraction, and stripping. First the ore is leached to get the desired metal into solution. Next, the now pregnant leach solution (PLS) is sent to the extraction stage where it is contacted with barren organic. The desired metal transfers from the aqueous phase, PLS, to the organic. The now barren aqueous, raffinate, is sent back to the leaching stage to be used again. The now loaded organic contains the desired metal and is sent to the stripping stage. During the stripping stage the loaded organic is contacted with lean electrolyte, and the metal transfers from the organic to the electrolyte. The electrolyte is now rich electrolyte and is used in the electrowinning process where the metal product is produced. During each stage once the metal is stripped from solution the barren organic and once again lean electrolyte are recycled back and used again in the process. Throughout each step in the process the concentration of the metal is being increased.

The extraction and stripping stages of the hydrometallurgical process are known as solvent extraction. The purpose of solvent extraction is to separate valuable metal from impurities and to increase the metal concentration. Solvent extraction is simply a mass transfer between two immiscible phases. It is based on principles of phase equilibria. The two phases are the aqueous and organic phases, and they are often immiscible because of their differences in solubilities. The aqueous phase contains the metal that is to be extracted, and the organic phase contains an extractant which does the extracting. Figure 1.1 shows the complete solvent extraction process while Figure 1.2 is only the extraction stage. 


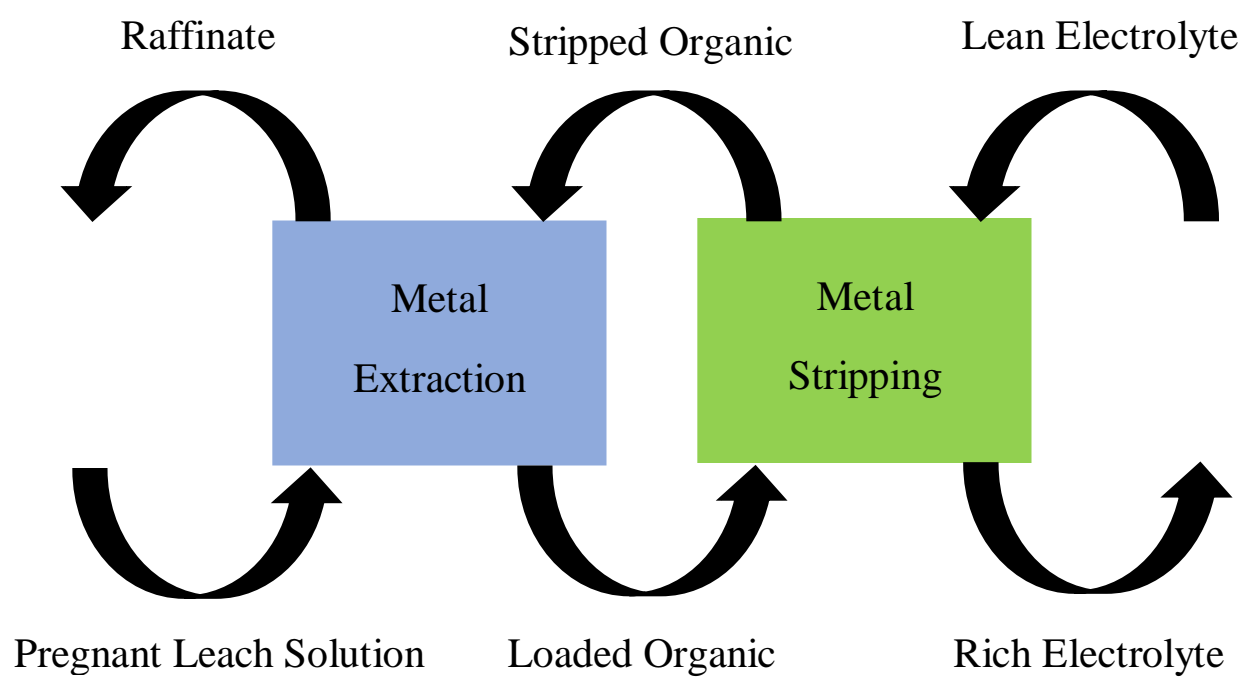

Figure 1.1: Solvent extraction process diagram.

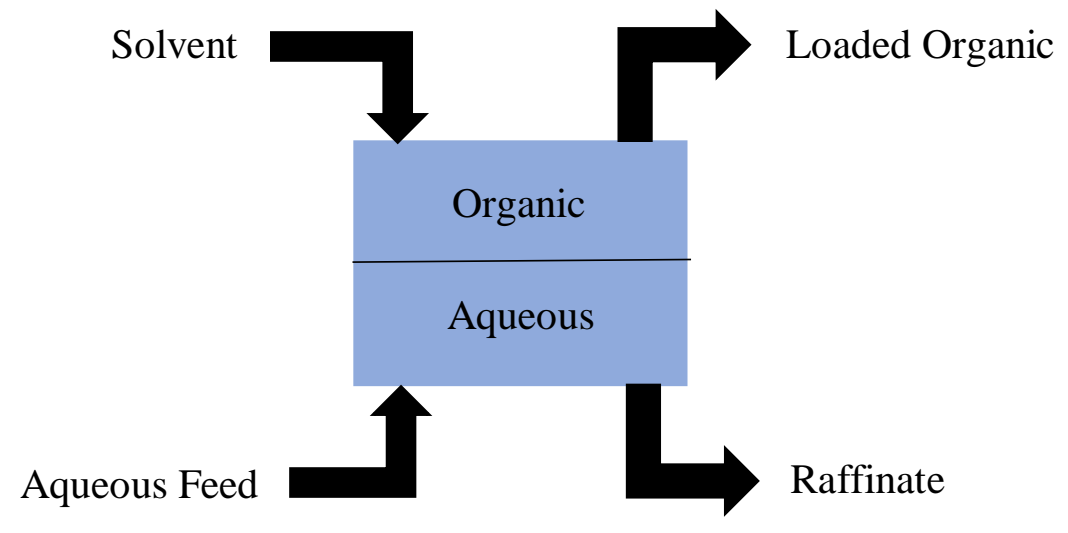

Figure 1.2: Extraction process diagram.

Looking at solvent extraction, Equations 1.1 and 1.2 illustrate the extraction reaction and stripping reaction, respectively. Where $\mathrm{M}$ is the desired metal, and the species with lines above them are the organic phase.

$$
\begin{aligned}
& M^{2+}+2 \overline{R H} \rightarrow \overline{R_{2} M}+2 H^{+} \\
& \overline{R_{2} M}+2 H^{+} \rightarrow M^{2+}+2 \overline{R H}
\end{aligned}
$$


As can be seen during extraction the metal in solution is transferred into the organic, and acid is produced. Then during stripping the loaded organic is contacted with acid in order for the metal to be stripped from the organic. As an example of how solvent extraction increases the concentration of the desired metal, copper PLS can have about $1.5 \mathrm{~g} / \mathrm{l}$ copper, and then by the time the copper is in the rich electrolyte, it can have a concentration of $50 \mathrm{~g} / \mathrm{l}$. Solvent extraction is a common method for recovering metal from leach solutions.

Extraction consists of mixing the organic and aqueous phases and then allowing the phases to settle and separate. One stage of extraction operationally consists of a mixer and a settler. The mixer to mix the aqueous feed with the solvent, organic, and the settler to separate the dispersion into discrete phases. Separation of the phases can be optimized by controlling the operating conditions. Extractant concentration, temperature, aqueous $\mathrm{pH}$, contact time, and concentration of the metal in the aqueous phase all contribute to how well the extraction and separation will occur. Extraction is usually done in a series of stages. A diagram of a stage is shown as Figure 1.3. This research is focused on the extraction process of hydrometallurgy.

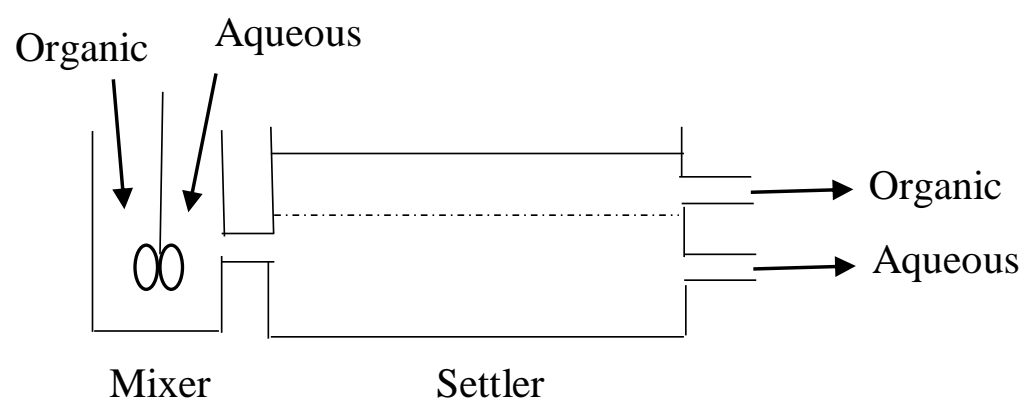

Figure 1.3: Operational extraction stage diagram.

Operating conditions are often studied to optimize solvent extraction plant performance. Common plots that are used to see how extraction will be effected by operating parameters include metal extraction versus $\mathrm{pH}$, distribution coefficient versus extractant concentration, and distribution isotherms. 


\subsection{RARE EARTH ELEMENTS}

The term rare earth refers to a particular group of elements. According to Fathi Habashi, "the term rare earths was originally only used for oxides, $\mathrm{R}_{2} \mathrm{O}_{3}$ " (Habashi 2013). The rare earths are commonly discussed as rare earth oxides (REOs). This group of elements is composed of the fifteen lanthanides, scandium, and yttrium. All of the elements in the rare earth group have similar chemical and physical properties. This results in "the isolation of groups of rare earth elements or of individual elements requiring costly separation and fractionation processes" (Habashi 2013). Among the elements labeled as rare earths, lanthanum, which is sometimes considered a transition metal instead of a lanthanide, scandium, and yttrium have different atomic structures than the lanthanide elements, cerium to lutetium (Habashi 2013). The rare earths have unique characteristics and require complex processing techniques.

Rare earth elements are lithophilic, meaning they occur in the earth's crust rather than in the core or mantle of the earth; this leads to these elements being concentrated in oxidic compounds including carbonates $\left(\mathrm{CO}_{2}{ }^{3-}\right)$, silicates $\left(\mathrm{SiO}_{4}{ }^{2-}\right)$, titano-tantaloniobates, and phosphates $\left(\mathrm{PO}_{4}{ }^{3-}\right)$ (Habashi 2013). Monazite sand, xenotime, bastnasite, and phosphate rock can contain rare earths, and they always occur in nature in association with each other (Habashi 2013). Table 1.1 from Fathi Habashi's Extractive Metallurgy of Rare Earths shows typical compositions of rare earth oxides in monazite, xenotime, and bastnasite (Habashi 2013). 
Table 1.1: Composition of Typical Rare Earth Bearing Minerals

\begin{tabular}{|c|c|c|c|}
\hline Lanthanide Oxide & Monazite (\%) & Xenotime (\%) & Bastnasite (\%) \\
\hline $\mathrm{La}_{2} \mathrm{O}_{3}$ & 23.0 & 0.5 & 32.0 \\
\hline $\mathrm{CeO}_{2}$ & 46.5 & 5.0 & 49.0 \\
\hline $\mathrm{Pr}_{6} \mathrm{O}_{11}$ & 5.1 & 0.7 & 4.4 \\
\hline $\mathrm{Nd}_{2} \mathrm{O}_{3}$ & 18.4 & 2.2 & 13.5 \\
\hline $\mathrm{Sm}_{2} \mathrm{O}_{3}$ & 2.3 & 1.9 & 0.5 \\
\hline $\mathrm{Eu}_{2} \mathrm{O}_{3}$ & 0.07 & 0.2 & 0.1 \\
\hline $\mathrm{Gd}_{2} \mathrm{O}_{3}$ & 1.7 & 4.0 & 0.3 \\
\hline $\mathrm{Tb}_{4} \mathrm{O}_{7}$ & 0.16 & 1.0 & 0.01 \\
\hline $\mathrm{Dy}_{2} \mathrm{O}_{3}$ & 0.52 & 8.7 & 0.03 \\
\hline $\mathrm{Ho}_{2} \mathrm{O}_{3}$ & 0.09 & 2.1 & 0.01 \\
\hline $\mathrm{Er}_{2} \mathrm{O}_{3}$ & 0.13 & 5.4 & 0.01 \\
\hline $\mathrm{Tm}_{2} \mathrm{O}_{3}$ & 0.013 & 0.9 & 0.2 \\
\hline $\mathrm{Yb}_{2} \mathrm{O}_{3}$ & 0.061 & 6.2 & 0.01 \\
\hline $\mathrm{Lu}_{2} \mathrm{O}_{3}$ & 0.006 & 0.4 & 0.1 \\
\hline $\mathrm{Y}_{2} \mathrm{O}_{3}$ & 2 & 60.8 & 0.1 \\
\hline
\end{tabular}

Monazite is an important source of lanthanum and cerium. Monazite is $23.0 \%$ lanthanum oxide and $46.5 \%$ cerium oxide. Large deposits of monazite sands can typically be found in India, Madagascar, and South Africa. Xenotime is a phosphate mineral which is mainly composed of yttrium orthophosphate. Xenotime is $60.8 \%$ yttrium oxide. Bastnasite is a fluorocarbonate mineral comprised $32 \%$ of lanthanum oxide and $49 \%$ cerium oxide. Bastnasite is "found in veins deposits, contact metamorphic zones, and pegmatites," and "it occurs as veins or disseminations in a complex of carbonate-silicate rocks, occurring with and related to alkaline intrusives, for example, in California" (Gupta and Krishnamurthy 2005). Major bastnasite deposits occur in California, Burundi, Madagascar, and Bayan Obo (Habashi 2013). "Complex minerals that are oxidic ores containing titanium, niobium, tantalum, uranium, and thorium can also contain rare earths (especially yttrium); examples of these minerals are Euxenite $(\mathrm{Y}, \mathrm{Ce})\left(\mathrm{Nb}, \mathrm{Ta}, \mathrm{Ti}_{2}\right)_{6} \mathrm{O}_{6}$, Samarskite $(\mathrm{Y}, \mathrm{Ce})_{4}\left(\mathrm{Nb}, \mathrm{Ta}, \mathrm{Ti}_{2} \mathrm{O}_{6}\right.$, Fergusonite $(\mathrm{Y})(\mathrm{Nb}, \mathrm{Ti}, \mathrm{Ta}) \mathrm{O}_{4}$, Betafite 
(U,Ca,Y, $\mathrm{Ce}_{2}(\mathrm{Nb}, \mathrm{Ta}, \mathrm{Ti})_{2} \mathrm{O}_{6}(\mathrm{OH})$ " (Habashi 2013). Rare earths always occur in conjunction with one another and can mostly be found in monazite, xenotime, and bastnasite.

\subsubsection{Resources}

Though the United States has a nearly complete import reliance on rare earth metals, there is a history of rare earth deposits and current rare earth mining occurring in the country. From 1887 until 1910 rare earths were produced in the United States from placer deposits in Burke County, North Carolina (Gupta and Krishnamurthy 2005). After production stopped in North Carolina, most of the monazite that the United States processed was imported from India and Brazil until the beginning of the Second World War; once the war started exports of monazite were restricted, and so production nearly ceased in the United States (Gupta and Krishnamurthy 2005). The elimination of exports and imports caused exploration for rare earth deposits and eventual identification and development of a few deposits in the United States. In 1948 the United States began producing monazite again when it was found to be a by-product of mining titanium minerals and zircon from beach sands in Florida (Gupta and Krishnamurthy 2005). The bastnasite deposit at Mountain Pass, California was discovered in 1949 which caused the United States to become a major producer of rare earth metals (Gupta and Krishnamurthy 2005). This discovery began a new era for rare earth production.

The Mountain Pass mine is a very important source of bastnasite ore. Mountain Pass is an open pit mine which contains barite, bastnasite, allanite, and monazite (Gupta and Krishnamurthy 2005). Annual production at Mountain Pass includes $308 \mathrm{kt}$ of ore and $24.7 \mathrm{kt}$ of rare earth oxides; between 1972 and 1989 a total of $293 \mathrm{kt}$ of rare earth oxides were produced (Gupta and Krishnamurthy 2005). This was the Mountain Pass era. Nowadays Mountain Pass frequently only operates intermittently and below full capacity. In fact, Molycorp has recently suspended all rare earth production at Mountain Pass due to financial hardships and the declining prices of rare earths ( "Molycorp To Move Its Mountain Pass Rare Earth Facility To 'Care and Maintenance' Mode"). Molycorp plans to continue their rare earth oxide production at their facilities in Estonia and China ("Molycorp To Move Its Mountain Pass Rare Earth Facility To 'Care and Maintenance' Mode”). This results in no rare earth production in the United States currently. 
Mountain Pass had its first production in 1965, and up until the mid-1980s it was the only source of commercial bastnasite in the world (Gupta and Krishnamurthy 2005). Gupta and Krishnamurthy show the different eras of rare earth production in Figure 1.4.

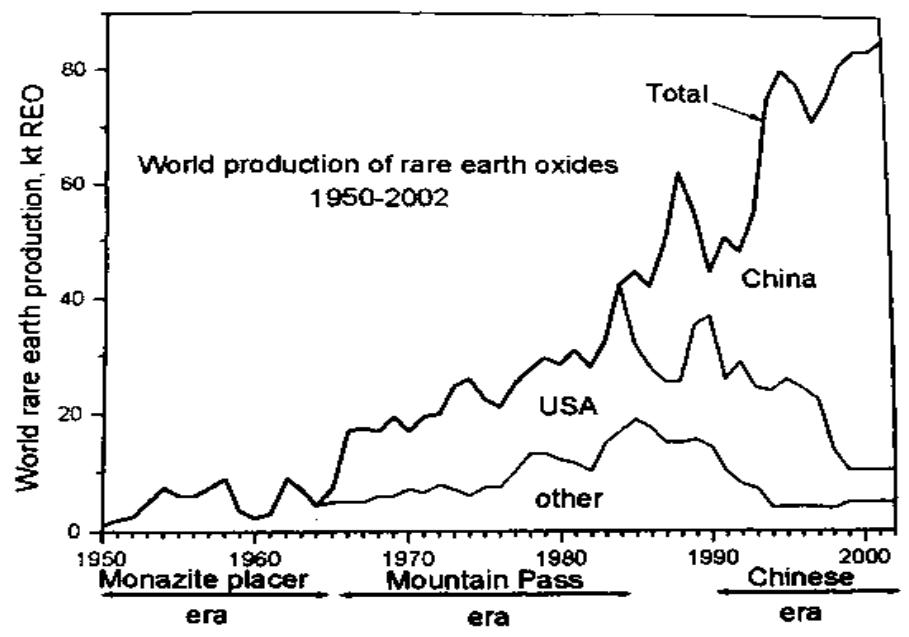

Figure 1.4: World rare earth production.

As can be seen the United States was the major producer of rare earth oxides from the mid-1960s until the mid-1980s. The late 1980s was a time of transitioning between the Mountain Pass era and the Chinese era. In 1989 when China was becoming the major REO producer, Mountain Pass still had 3,375 kt resources of bastnasite and 2,503 kt resources of rare earth oxides (Gupta and Krishnamurthy 2005). From the mid-1990s through today China is the major producer of rare earths in the world. By 2000 "more than 90\% of separated REE used in the U.S. were from Chinese rare earth resources" (Gupta and Krishnamurthy 2005). Table 1.2 shows more detailed data of what countries were producing rare earth oxides in metric tons of rare earths oxides as the production transitioned from Mountain Pass to China (Gupta and Krishnamurthy 2005). In 1986 the United States had 11,094 metric tons of rare earth oxide mine production while China only had 6,750 tons of production. By 2002 the U.S. was only producing 5,000 metric tons of REO annually while China was producing up to 75,000 tons annually. 
Table 1.2: World Mine Production of Rare Earths (metric tons of REO)

\begin{tabular}{|c|c|c|c|c|c|c|c|}
\hline & U.S. & Australia & Brazil & India & Malaysia & China & $\begin{array}{c}\text { Former } \\
\text { USSR }\end{array}$ \\
\hline 1986 & 11094 & 5820 & 3300 & 2200 & 3300 & 6750 & \\
\hline 1987 & 16710 & 6600 & 1100 & 2200 & 3300 & 15100 & \\
\hline 1988 & 11533 & 6530 & 1100 & 2200 & 3300 & 18660 & 8500 \\
\hline 1989 & 21875 & 7700 & 2280 & 2060 & 3300 & 25220 & 8500 \\
\hline 1990 & 22700 & 6050 & 911 & 2500 & 1830 & 16500 & 8500 \\
\hline 1991 & 16500 & 3850 & 719 & 2200 & 1090 & 16150 & 8500 \\
\hline 1992 & 20700 & 3300 & 396 & 2200 & 427 & 21340 & 8000 \\
\hline 1993 & 17800 & 1650 & 400 & 2500 & 224 & 22100 & 4500 \\
\hline 1994 & 20700 & - & 256 & 2500 & 234 & 30700 & 2000 \\
\hline 1995 & 22200 & - & 103 & 2700 & 448 & 48000 & 2000 \\
\hline 1996 & 20400 & - & - & 2700 & 340 & 55000 & 2000 \\
\hline 1997 & 100000 & - & - & 2700 & 418 & 53000 & 2000 \\
\hline 1998 & 5000 & - & - & 2700 & 202 & 60000 & 2000 \\
\hline 1999 & 5000 & - & - & 2700 & 625 & 70000 & 2000 \\
\hline 2000 & 5000 & - & - & 2700 & 446 & 73000 & 2000 \\
\hline 2001 & 5000 & - & 200 & 2700 & 450 & 73000 & 2000 \\
\hline 2002 & 5000 & - & 200 & 2700 & 450 & 75000 & 2000 \\
\hline
\end{tabular}

The ores in California and Bayan Obo are very similar in composition. Table 1.3 shows a comparison of compositions of bastnasite ore at Mountain Pass and bastnasite in Bayan Obo, China (Gupta and Krishnamurthy 2005). The most notable differences are in the lanthanum and yttrium. Mountain Pass bastnasite has approximately 10\% more lanthanum than Bayan Obo ore, while Bayan Obo has five times more yttrium than Mountain Pass does. The United States had its time being the major rare earth producer in the world, but China is now responsible for the majority of rare earth production. 
Table 1.3: Composition of Bastnasite Ores

\begin{tabular}{|c|c|c|}
\hline Rare Earth & $\begin{array}{c}\text { Bastnasite, Mountain } \\
\text { Pass, California, U.S. } \\
(\%)\end{array}$ & $\begin{array}{c}\text { Bastnasite, Bayan } \\
\text { Obo, Nei Monggol, } \\
\text { China (\%) }\end{array}$ \\
\hline $\mathrm{La}$ & 33.2000 & 23.0000 \\
\hline $\mathrm{Ce}$ & 49.1000 & 50.0000 \\
\hline $\operatorname{Pr}$ & 4.3400 & 6.2000 \\
\hline $\mathrm{Nd}$ & 12.0000 & 18.5000 \\
\hline $\mathrm{Sm}$ & 0.7890 & 0.8000 \\
\hline $\mathrm{Eu}$ & 0.1180 & 0.2000 \\
\hline $\mathrm{Gd}$ & 0.1660 & 0.7000 \\
\hline $\mathrm{Tb}$ & 0.0159 & 0.1000 \\
\hline Dy & 0.0312 & 0.1000 \\
\hline Ho & 0.0051 & Trace \\
\hline $\mathrm{Er}$ & 0.0035 & Trace \\
\hline $\mathrm{Tm}$ & 0.0009 & Trace \\
\hline $\mathrm{Yb}$ & 0.0006 & Trace \\
\hline $\mathrm{Lu}$ & 0.0001 & Trace \\
\hline $\mathrm{Y}$ & 0.0913 & 0.5000 \\
\hline
\end{tabular}

Now that where rare earth deposits are found in the world has been discussed, the abundance of the rare earths in the earth's crust should be noted. Considering crustal abundance alone, the rare earths all together are not actually that "rare". They occur widely but are distributed in very low concentrations. Table 1.4 and Figure 1.5 show the abundance of each rare earth in parts per million, ppm, in the earth's crust (Gupta and Krishnamurthy 2005). Table 1.4 contains values from five different sources, and the data varies. It is not known for certain what the crustal abundance of each rare earth is exactly. Combined together the rare earths are almost as abundant as carbon, but because they are widely distributed in low concentrations and have 
complex mineralization, they are "rare". This leads to how the rare earths are processed and fractionated.

Table 1.4: Crustal Abundance of Rare Earths (ppm)

\begin{tabular}{|c|c|c|c|c|c|}
\hline Element & $\begin{array}{c}\text { Kleber and } \\
\text { Love 1963 }\end{array}$ & $\begin{array}{c}\text { Jackson and } \\
\text { Christiansen } \\
1993\end{array}$ & $\begin{array}{c}\text { Sabot and } \\
\text { Maestro 1995 }\end{array}$ & McGill 1997 & Lide 1997 \\
\hline $\mathrm{Sc}$ & 10 & & 10 & $5-10$ & 22 \\
\hline $\mathrm{Y}$ & 28 & 29 & 28 & $28-70$ & 33 \\
\hline $\mathrm{La}$ & 18 & 29 & 18 & $5-18$ & 39 \\
\hline $\mathrm{Ce}$ & 46 & 70 & 46 & $20-46$ & 66.5 \\
\hline $\mathrm{Pr}$ & 5.5 & 9 & 5.5 & $3.5-5.5$ & 9.2 \\
\hline $\mathrm{Nd}$ & 24 & 37 & 24 & $12-24$ & 41.5 \\
\hline $\mathrm{Sm}$ & 6.5 & 8 & 6.5 & $4.5-7$ & 7.05 \\
\hline $\mathrm{Eu}$ & 0.5 & 1.3 & 0.5 & $0.14-1.1$ & 2.0 \\
\hline $\mathrm{Gd}$ & 6.4 & 8.0 & 6.4 & $4.5-6.4$ & 6.2 \\
\hline $\mathrm{Tb}$ & 0.9 & 2.5 & 0.9 & $0.7-1$ & 1.2 \\
\hline $\mathrm{Dy}$ & 5.0 & 5.0 & 5.0 & $4.5-7.5$ & 5.2 \\
\hline $\mathrm{Ho}$ & 1.2 & 1.7 & 1.2 & $0.7-1.2$ & 1.3 \\
\hline $\mathrm{Er}$ & 4.0 & 3.3 & 4.0 & $2.5-6.5$ & 3.5 \\
\hline $\mathrm{Tm}$ & 0.4 & 0.27 & 0.4 & $0.2-1$ & 0.52 \\
\hline $\mathrm{Yb}$ & 2.7 & 0.33 & 2.7 & $2.7-8$ & 3.2 \\
\hline $\mathrm{Lu}$ & 0.8 & 0.8 & 0.8 & $0.8-1.7$ & 0.8 \\
\hline
\end{tabular}

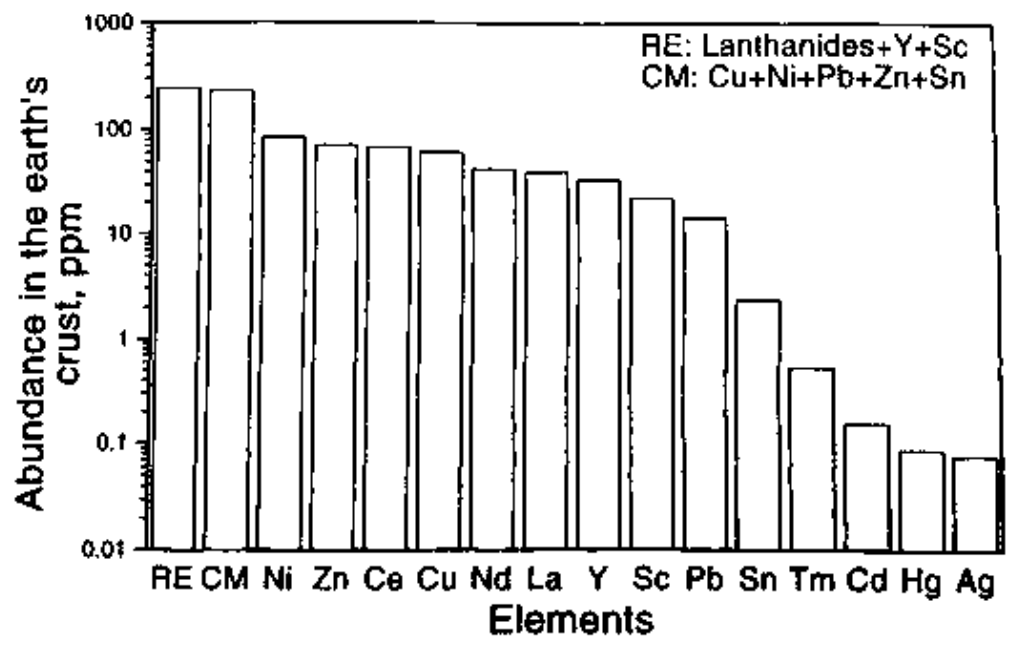

Figure 1.5: Crustal abundance of the rare earths. 


\subsubsection{Recovery of Rare Earth Elements from Conventional Resources}

There are a number of factors considered when determining if it is beneficial to extract metal from ore. The "extent to which metal is used in technology and is available commercially is determined not only by its crustal abundance but also by many other factors" (Gupta and Krishnamurthy 2005). According to Gupta and Krishnamurthy (2005), there are three main factors that determine how available rare earths are and what they are used for:

1. The degree of metal concentration by natural processes into ore deposits

2. The relative ease of obtaining the ore from the environment

3. The feasibility of extracting the metal from the ore.

Here the feasibility of extracting the metal from the ore is the focus.

Processing of minerals can be a complicated process, especially with rare earths. The rare earth elements require complex processes for extraction and fractionation. This is because the rare earths all have similar properties. There are a variety of methods for extracting rare earths from rare earth containing ores, some of which are more efficient and economical than others. Processing of rare earths has advanced from fractional crystallization to ion exchange and hydrometallurgy. Some of the processes will now be discussed.

After mining and physical beneficiation, chemical treatment is the first step in recovering rare earths from conventional resources such as rare earth containing minerals. Recovery of rare earths from bastnasite ore is discussed as an example of recovery from a conventional resource. The chemical treatment of bastnasite can include, leaching, roasting, calcining, or a number of other processes. This chemical treatment can start with crude ore or with the concentrate produced from beneficiation. Figure 1.6 shows one example process for the recovery of these metals from bastnasite ore (Gupta and Krishnamurthy 2005). 


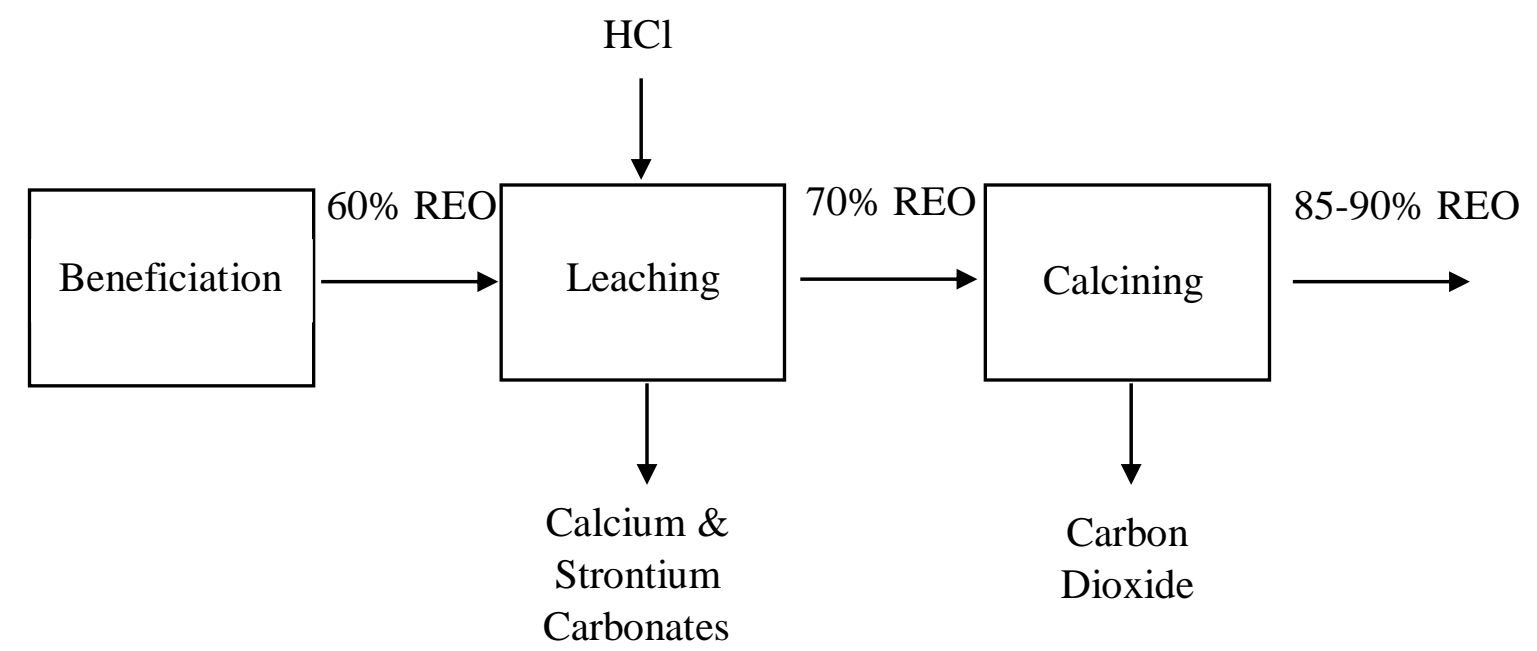

Figure 1.6: Recovery of rare earth oxides from bastnasite ore.

In this process leaching with hydrochloric acid is employed in order to remove the calcium and strontium carbonates. The leaching product is then subjected to calcining to remove the carbon dioxide. Through each stage of this process the concentration of the rare earth oxides is increased. This is just one method for recovering metals from these ores.

There are a number of methods suggested for recovering metals from bastnasite ore. The decomposition of bastnasite ore has been widely studied. One process suggested involved nitric acid digestion and solvent extraction. Using this method approximately $98 \%$ of the rare earths were recovered from crude bastnasite ore comprised of 7-10\% REO (Gupta and Krishnamurthy 2005). Decomposition of bastnasite ore has also been successfully achieved using sulfuric acid. Berber et al. (1960) sulfated bastnasite concentrate with concentrated sulfuric acid and then used calcination to recover nearly $100 \%$ of the rare earths from the $60 \%$ REO concentrate (Berber et al. 1960). In this process carbon dioxide, fluorine, and silica were removed from the sulfating with sulfuric acid, and then the calcination made the remaining gangue material insoluble. Rare earths have also been recovered from bastnasite concentrate as water soluble sulfates by dissolving the concentrate in warm, concentrated sulfuric acid (Shaw 1959). This sulfuric acid process has been used commercially for recovering rare earths (Kaczmarek 1981). Rare earths have also have been successfully extracted from ore by leaching with hydrochloric acid. There are many methods for the processing of bastnasite ore. 
In California, Molycorp recovers rare earths from bastnasite concentrate. The REO containing concentrate is roasted in air, and then the calcine is treated with hydrochloric acid (World Mining 1966). The roasting removes the carbon dioxide and oxidizes the cerium. The hydrochloric acid treatment dissolves the noncerium rare earths producing a product containing 65-70\% REO with 55-60\% $\mathrm{CeO}_{2}$ (Gupta and Krishnamurthy 2005). Solvent extraction is then employed for the separation and purification of the rare earths.

China and the United Kingdom utilized different processes for the recovery of rare earths from their respective bastnasite concentrates than does Molycorp. In China, the concentrate is heated with sulfuric acid to destroy the fluorocarbonate matrix and convert the rare earths to their respective sulfates (Gupta and Krishnamurthy 2005). The remainder of the process includes precipitating the rare earths using water and sodium chloride, converting the sulfate to hydroxides by digestion, and then dissolving the hydroxides in hydrochloric acid (Gupta and Krishnamurthy 2005). Solvent extraction is then utilized for further processing. In the United Kingdom, the concentrate is treated with caustic soda and then dissolved in hydrochloric acid to produce a rare earth chloride solution (Gupta and Krishnamurthy 2005). Due to differing ore compositions and characteristics there is not one unified method for the chemical treatment of bastnasite ores.

After chemical treatment ion exchange is one method for separation and purification of the rare earths. Ion exchange yields large quantities of high purity individual rare earths, but the resin used in ion exchange does not have selectivity for individual lanthanides. Therefore, separation cannot be achieved. To fractionate the rare earths, their different affinities toward complexing agents in solution is utilized (Habashi 2013). Obtaining each of the lanthanides at about $99.99 \%$ purity requires 30 columns on a commercial scale in a process that has low throughput (Habashi 2013).

Solvent extraction is an alternative to ion exchange for the processing of rare earths. There are benefits to using solvent extraction with rare earths. One benefit is that the loading onto the extractant in the organic can be in the range of approximately 180 grams REO per liter (Gupta and Krishnamurthy 2005). This results in aqueous solutions containing about 100-140 grams of REOs per liter can be used in the process (Gupta and Krishnamurthy 2005). These parameters result in benefits such as the ability of the required equipment for the solvent 
extraction to be very small. (McGill 1993). Solvent extraction has become common globally for rare earth processing.

There are differing solvent extraction processes utilized for fractionation of the rare earths, but the process used at Molycorp will be focused on. The solvent used for separating the rare earths from leach solution of bastnasite ore is di (2-ethylhexyl) phosphoric acid known as D2EHPA. Its chemical structure is shown in Figure 1.7.

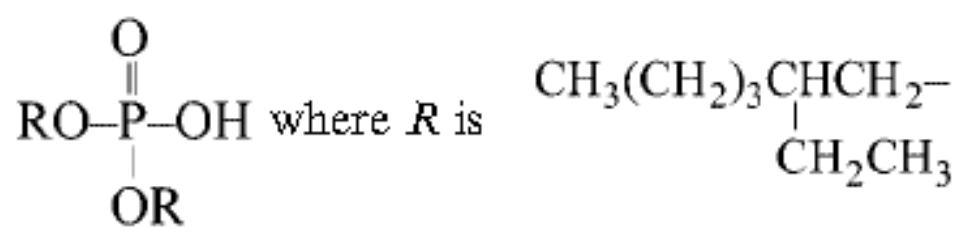

Figure 1.7: D2EHPA Chemical Structure

The Molycorp process for the separation of rare earths consists of numerous extraction steps with each including multiple stages of contact with the extractant and the stripping agent under various concentrations and phase ratios. A diagram of Molycorp's process with its multiple extraction stages is shown as Figure 1.8 (Habashi 2013). Molycorp's processing plant is fully computerized and automated (Habashi 2013). Processing of rare earths is still a tedious task, but the technology has definitely advanced.

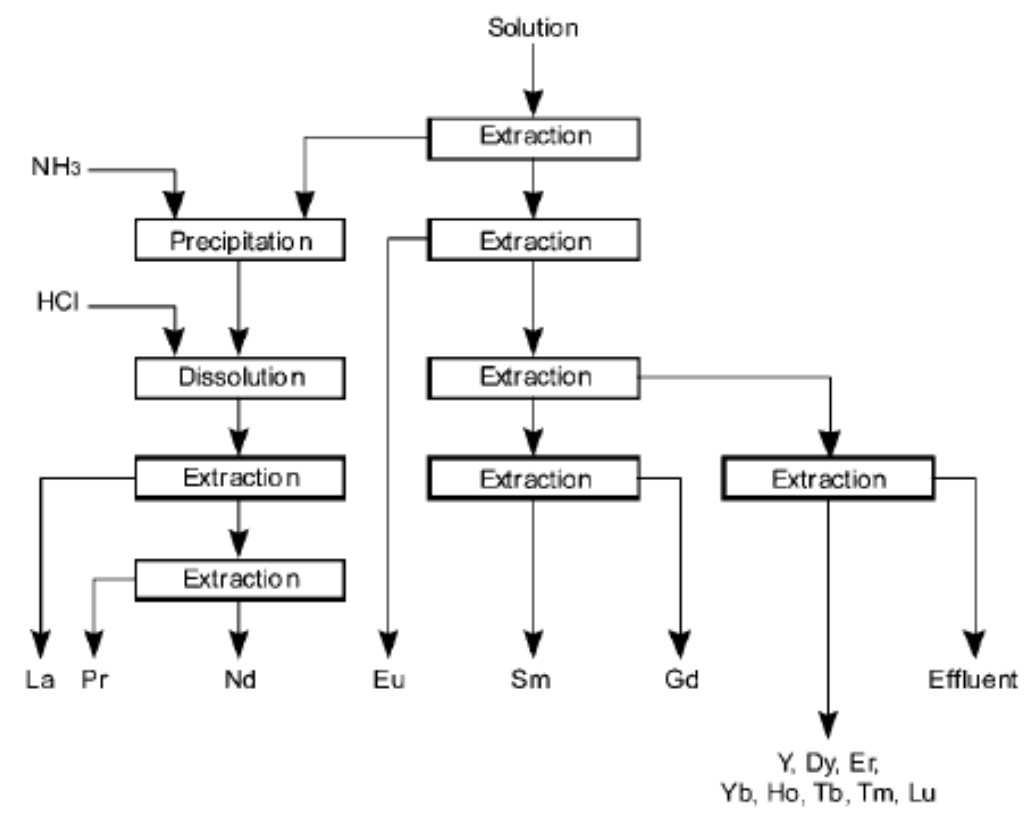

Figure 1.8: Molycorp's rare earth solvent extraction process. 


\subsubsection{Yttrium and Neodymium}

The research presented in this thesis focuses on two rare earth elements: yttrium and neodymium. Yttria was discovered in 1794 by J. Gadolin, named by A.G. Ekeberg, and confirmed by M. Delafontaine (Gupta and Krishnamurthy 2005). Yttria was named after the place where it was discovered, Ytterby. In 1886 neodymium was discovered by C.A. von Welsbach, named by C.A. von Welsbach, and confirmed by A. Bettendorf (Gupta and Krishnamurthy 2005). It was named for its chemical behavior. Important chemical properties of yttrium and neodymium are shown in Table 1.5 .

Table 1.5: Chemical Properties of Yttrium and Neodymium

\begin{tabular}{|c|c|c|}
\hline Property & Yttrium & Neodymium \\
\hline Atomic Number & 39 & 60 \\
\hline Atomic Weight $(\mathrm{g})$ & 88.906 & 144.240 \\
\hline Density $\left(\mathrm{g} / \mathrm{cm}^{3}\right)$ & 4.469 & 1.008 \\
\hline Electronegativity & 1.177 & 1021 \\
\hline Melting Point $\left({ }^{\circ} \mathrm{C}\right)$ & 1522 & 3068 \\
\hline Boiling Point $\left({ }^{\circ} \mathrm{C}\right)$ & 3338 & {$[\mathrm{Xe}] 4 \mathrm{f}^{4} 6 \mathrm{~s}^{2}$} \\
\hline Electron Configuration & {$[\mathrm{Kr}] 4 \mathrm{~d}^{1} 5 \mathrm{~s}^{2}$} & \\
\hline
\end{tabular}

The United States has a nearly $100 \%$ import reliance on rare earths including yttrium and neodymium. As was shown in Table 1.3 the bastnasite ore at Mountain Pass is $0.0913 \%$ yttrium and $12 \%$ neodymium. In recent years no yttrium has been produced in the U.S. but small amounts of neodymium are produced when Mountain Pass is operating. In 2013 and 2014 the United States consumed approximately 200 tons of yttrium oxide each year (Gambogi 2015). The majority of yttrium and neodymium consumed in the U.S. is imported from China. This comes at a cost since $99.999 \%$ pure yttrium oxide cost $\$ 15-17$ per kilogram in 2014 , and $99.9 \%$ pure yttrium metal cost \$55-65 in the same year (Gambogi 2015). Concurrently, neodymium oxide with greater than 99\% purity was valued at \$56-60 per kilogram in 2014 (Gambogi 2015). As of May 2015 yttrium metal was $\$ 77$ per kilogram, yttrium oxide was \$15 per kilogram, neodymium metal was $\$ 87$ per kilogram, and neodymium oxide \$59 per kilogram ("Mineral 
Prices" 2015). The lack of domestic production of rare earths causes the United States to be reliant on and pay other countries for rare earth metals.

Both yttrium and neodymium are used in the production of important materials. The main end use of yttrium is as an additive in aluminum and magnesium alloys in order to increase their strength (Emsley 2014). Other uses for yttrium or yttrium oxide include: as a component in microwave filters for radar, as a component in lasers that are strong enough to cut through metals, in white LED lights, as an additive to glass to make it more resistant to heat and shock, and also in the manufacture of superconductors. The main end use of neodymium is in an alloy with iron and boron in order to produce permanent magnets (Emsley 2014). Neodymium can also be found in glass used to make lasers and as a catalyst in polymerization reactions. In recent years substitutions have been used for the rare earths because of the cost of the REEs in the applications involving the metallurgical and magnetic properties of the rare earths, but for other applications substitutions are not available (Gupta and Krishnamurthy 2005). "Applications of rare earths in certain polishing applications, catalysts, phosphors, magnets, optical glass components, coloring and decoloring of glass, pigments, and intensifiers of x-rays will be long lasting" (Gupta and Krishnamurthy 2005). Yttrium and neodymium are both necessary in that they are unique, and so it is very difficult if not impossible to find substitutes for them in the applications that they are used for.

Since both yttrium and neodymium are found in the earth's crust at low concentrations and are widely distributed, it is advantageous to extract them whenever present. Additionally, less than 10 percent of both yttrium and neodymium are recycled, so new sources are continually needed (Emsley 2014). Yttrium, neodymium, and a number of other rare earth elements have been found in pregnant leach solutions (PLS) from copper mining operations. The recovery of yttrium and neodymium from copper PLS represents an important alternative resource to traditional ores and concentrates. The purpose of this research is to investigate the recovery of yttrium and neodymium from copper sulfate solution and from copper PLS using solvent extraction. 


\subsection{LITERATURE REVIEW}

\subsubsection{Extraction of Dissolved Metals from Copper PLS}

The idea of extracting dissolved metals from copper PLS goes hundreds of years back to when the first metals were put into solution by copper heap leaching at Rio Tinto, Spain. Since that time metals such as copper and gold have commonly been put into solution and then recovered, but other metals are dissolved into the PLS. Much research has been done in recent years on the extraction of dissolved metals that have not traditionally been recovered from copper PLS. Specifically, cobalt, nickel, uranium, and rhenium are of interest.

Nebeker et al. (2014) have discovered a method for extracting cobalt and nickel from copper raffinate. The cobalt and nickel can be extracted from the copper raffinate that is produced from the solvent extraction process which contains copper, ferric iron, cobalt, and nickel. The first step in this process is the pretreatment of the raffinate. The pretreatment process includes raising the $\mathrm{pH}$, removing solids, and/or reducing ferric iron to ferrous iron. The next step removes all copper from the raffinate by an ion exchange resin that is selective for copper. Next, an ion exchange resin selective for cobalt and nickel is used to recovery the cobalt and nickel, which are then separated as they are removed from the resin.

Marston et al. (2015) also proposed a method for recovering nickel and cobalt by ion exchange. The proposed process is continuous ion exchange which results in the extraction of the metals from PLS. This process first extracts the nickel from solution by using an ion exchange resin that is selective for nickel. This results in a raffinate solution which contains cobalt. Nickel is removed from the resin by using sulfuric acid. The $\mathrm{pH}$ of the cobalt solution is then adjusted to at least 2.3, and then the solution is passed through an ion exchange bed so that the cobalt is loaded onto the ion exchange resin. These steps are continuously repeated until the concentration of the desired metals is increased.

George, Ross, and Prater (1967) at the Salt Lake City Metallurgy Research Center successfully determined a method for recovering uranium from copper PLS at Kennecott Copper Corporation's Bingham Canyon mine. The concentration of $\mathrm{U}_{3} \mathrm{O}_{8}$ in copper leach solutions ranges from 2 to 15 parts per million, ppm, and at Bingham Canyon the $\mathrm{U}_{3} \mathrm{O}_{8}$ concentration in the PLS is $13 \mathrm{ppm}$. Ion exchange can be used to recover the uranium. Countercurrent ion exchange columns were used in this study. George, Ross, and Prater (1967) also tested the 
recovery the uranium by solvent extraction using tertiary amines and found that this was not successful.

Rezkallah (2014) determined a method for extracting uranium from pregnant liquor solutions containing chloride by using an ion exchange resin. An amino phosphonic functionalized resin was utilized. The uranium was recovered from the PLS using the resin.

Udayar et al. (2011) describe an industrial application where uranium was recovered from leach solutions by resin-in-pulp techniques. Recovery of uranium from South African gold ore was tested at a pilot plant, and the process was also used at a commercial scale at a plant processing gold ore prior to the cyanidation step. The pilot plant at Mintek ran with gold ore which contained 150-350 grams per ton of $U_{3} O_{8}$. The plant was designed to obtain 43 grams per liter $U_{3} O_{8}$ loaded on the resin from a leached pulp which contained 180 milligrams per liter $\mathrm{U}_{3} \mathrm{O}_{8}$. These studies demonstrated the successful recovery of uranium from gold ores.

Nebeker (2012) has invented a method to recovery rhenium from copper solvent extraction solution. The rhenium is recovered by ion exchange. First, the solvent extraction solution is filtered. Ion exchange resins which are selective for rhenium absorb rhenium from the filtered solution. After the resin is washed, rhenium is removed from the resin using three consecutive amounts of eluent. The second amount produces the rhenium which is collected.

Freeport-McMoRan Inc. also developed a process for the recovery of rhenium from copper leach solutions (Bryce et al. 2014). Freeport-McMoRan Inc.'s process utilizes carbon adsorption followed by ion exchange or solvent extraction. This process increases the concentration of rhenium from less than $1 \mathrm{ppm}$ up to 15 grams per liter. The processing plant at Freeport-McMoRan Inc.'s Sierrita Operations has demonstrated the success of this process for recovering rhenium from copper PLS.

\subsubsection{Extraction of Metal Ions Using Amines}

Research has been done to study the feasibility of using amines for the extraction of metal ions. Leddicotte and Moore (1952) were the first to record the use of amines in solvent extraction of metallic elements from solution. It was found that niobium could successfully be extracted from strong hydrochloric acid with a solution of methyldioctylamine (a tertiary amine) in xylene (Leddicotte and Moore 1952). Crouse and Denis (1955) showed the success of using 
amines to extract thorium, uranium, and rare earths from sulfuric acid digests of monazite sands, and Lucas and Ritcey (1971) proved it possible to extract thorium and uranium from leach liquor that resulted from sulfuric acid leaching of uranium ore. Coleman (1963) also discussed the use of primary, secondary, tertiary, and quaternary ammoniums for extracting metal ions from sulfate, chloride, and nitrate systems. Ritcey and Ashbrook (1984) agree that there are now solvent extraction processes which use primary, secondary, and tertiary amines as extractants. Since the discovery of using amines in solvent extraction they have become more commonly used as extractants.

Extraction using a primary amine, Primene JM-T, has been studied specifically. Nekovar and Schrotterova (2000) studied the extraction of metals using Primene JM-T as the extractant. They studied the extraction of vanadium, molybdenum, and tungsten from sulphuric acid solutions in the range of $\mathrm{pH} 2$ to $\mathrm{pH}$ 6.5. Reactions of amine salts forming and anion exchanges were noted by Nekovar and Schrotterova (2000). Primene JM-T was successfully able to extract these metals, and it also possible to use it for extraction from weak acidic solutions.

\subsubsection{Extraction of Trivalent Rare Earths with Primene JM-T}

Research has been conducted which shows the success of Primene JM-T as an extractant for the recovery of trivalent rare earths. The research by Ichikawa (1961) shows the process of anion exchange and the use of amines in the extraction of rare earth elements in nitric acid. For the anion exchange process Dowex 1, X8 (100 200) mesh was used as the anion exchange resin. For the amine testes kerosene was used as the diluent while Primene JM-T, Amberlite LA-2, and tri-n-octyl amine were used as primary, secondary, and tertiary amines, respectively, as extractants. The amine extraction experiments consisted of $2 \mathrm{~mL}$ of $30 \%$ kerosene solution of amine being shaken for 1 minute with $2 \mathrm{~mL}$ of nitric acid solution of rare earth element. The results for anion exchange and amine extraction followed the same trend, and it was concluded that both processes follow similar mechanisms.

Work done by Kawamura et al. (1963) researched the use of Primene JM-T in kerosene as the extractant to recover trivalent rare earths and tetravalent cerium. Kawamura et al. (1963) found that Primene JM-T is an effective extractant when using kerosene, hexane, cyclohexane, or xylene as diluents. The rare earths could not be extracted at low $\mathrm{pH}$ values using $0.2 \mathrm{M}$ Primene 
JM-T. Extraction was achieved when $\mathrm{pH}$ was greater than 1. This is in agreement with many other research studies.

Rice's (1965) work shows the success of Primene JM-T as an extractant for the separation of rare earths by solvent extraction. This research studied the liquid-liquid fractional solvent extraction of rare earth sulfate salts by utilizing an amine. The aqueous phase used in these tests included chelating agents such as EDTA and diethylenetriaminepentaacetic acid. Primene JM-T in hexane was used successfully as the extractant.

\subsubsection{Extraction of Yttrium from Sulfate Solutions}

Rice and Stone (1962) studied the extraction of rare earths from sulfate solutions using amines. Extraction from the sulfate solutions as well as separation of the rare earths was studied. For the extraction studies the aqueous phase contained 0.01 to $0.03 \mathrm{M}$ lanthanum, cerium (III), and yttrium sulfates at $\mathrm{pH}$ of 1.1 to 1.2 , and amine concentrations were tested in the range of 0.1 to $0.5 \mathrm{M}$. It was found that $\mathrm{pH}$ and type of amine affected extraction of the rare earths the most. Primene 81-R (primary aliphatic amine), N-benzylheptadecylamine (BHDA) (secondary amine), and Primene JM-T (primary amine) were the most effective extractants for the rare-earth elements. Primene JM-T was the most successful extractant when tested with various diluents.

Effect of $\mathrm{pH}$ on the extraction of yttrium using Primene 81-R was studied (Rice and Stone 1962). Conditions used included 0.01 $\mathrm{M} \mathrm{Y}_{2} \mathrm{O}_{3}$ and 0.3 $\mathrm{M}$ Primene 81-R. Yttrium could not be extracted at $\mathrm{pH} 1$. At higher $\mathrm{pH}$ Primene 81-R was an effective extractant. $70 \%$ extraction of yttrium was achieved at $\mathrm{pH}$ 7. Primene 81-R was only successful as an extractant for rare earths at higher $\mathrm{pH}$ values.

The research of Levenson, Sole and Hiskey (1992) clearly shows the ability of a primary amine (Primene JM-T) to successfully extract yttrium at low $\mathrm{pH}$ from sulfate solutions. These experiments were performed at the following conditions: $10^{-3} \mathrm{M}$ yttrium solution, $0.5 \mathrm{M} \mathrm{Na}_{2} \mathrm{SO}_{4}$, and 5\% Primene JM-T in Escaid. Primene JM-T shows nearly complete extraction of yttrium at $\mathrm{pH}$ values above 1.5. On the other hand, secondary, tertiary, and quaternary amines exhibit very low yttrium extraction below $\mathrm{pH}$ 7. Figure 1.9 shows these results. It is interesting to note that yttrium extraction using Adogen 283, Adogen 364, and Aliquat 336 display similar pH behavior. A single dashed curve is used to demonstrate the general response to $\mathrm{pH}$ for these extractants. 


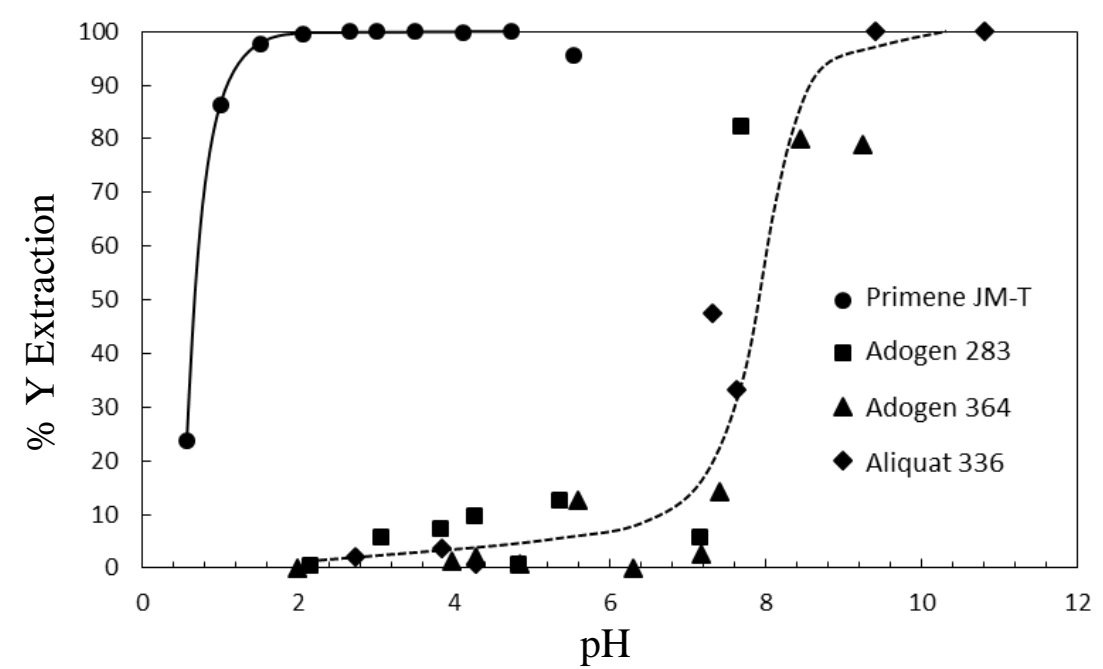

Figure 1.9 Percent yttrium extraction as a function of $\mathrm{pH}$ for primary, secondary, tertiary, and quaterinary amines.

Desouky et al. (2009) studied the extraction of yttrium from acidic sulfate solutions using Primene JM-T. In this research the effect of extractant concentration, diluent type, equilibrium $\mathrm{pH}$ and time, and temperature on extraction were studied. Standard conditions for Desouky et al.'s (2009) research included using a stock solution of $8.86 \times 10^{-3} \mathrm{M}$ yttrium prepared using $\mathrm{Y}_{2} \mathrm{O}_{3}, 5$ minute contact time, aqueous $\mathrm{pH} 1.5$, and room temperature.

Desouky et al.'s (2009) research concluded many things about the extraction of yttrium from sulfate solutions. For diluents, aliphatic kerosene diluents were preferred compared to aromatic diluents. Kerosene was the preferred diluent due to its extraction efficiency, inexpensive cost, and environmental and safety factors. Additionally, in the range of 0.1 to $0.5 \mathrm{M}$ extractant concentration, yttrium recovery increased with an increase in Primene JM-T concentration up to $0.4 \mathrm{M}$. Maximum extraction occurred at $\mathrm{pH} 1.56$, and complete extraction occurred within 5 minutes of contact time. Extraction was most favorable at room temperature because the reaction is an exothermic process. The most effective extraction occurred under the following conditions: room temperature, 5 minute contact time, 3 stages of extraction, $0.4 \mathrm{M}$ Primene JM-T concentration, $\mathrm{pH}$ 1.5, and 1:1 A:O ratio. 


\subsection{RARE EARTHS IN COPPER PORPHYRY DEPOSITS}

It has been proven that rare earth elements are geologically present with copper and other minerals in porphyry deposits. Lang and Titley (1998) and Anthony and Titley (1988) discuss the genesis of porphyry copper deposits specifically in Arizona and how rare earths came to be in the mineralization. According to Barton (2015) the fundamental control on rare earth element distribution is magma-water partitioning. Since rare earths do not fit into the structures of the common igneous minerals, the crystallization of the magma forces them into the remaining melt which exsolves a magmatic water when the pressure drops (Barton 2015). The rare earths enter this water phase. As a result the rare earths are found in the minerals that precipitate from the magmatic fluid which also contains copper, molybdenum, and other metals; so the rare earth elements end up being associated with the ore-bearing parts of the porphyry deposit (Barton 2015). Rare earths have been found in copper leach solutions in Arizona. Table 1.6 shows the rare earth composition of PLS from two of these mining operations. The remainder of the composition of these solution is shown in Table 1.7. There is evidence that rare earths are found with metals such as copper and molybdenum.

Table 1.6: Rare Earth Element Composition of PLS in Arizona

\begin{tabular}{|c|c|c|c|c|c|c|c|c|}
\hline \multirow{2}{*}{ PLS } & \multicolumn{9}{|c|}{ Concentration (ppm) } \\
\cline { 2 - 9 } & Ce & La & Nd & Pr & Sm & Th & U & Y \\
\hline A & $<1$ & $<1$ & 2.1 & $<1$ & 1 & $<1$ & 1 & 14.9 \\
\hline B & 8 & 1 & 10 & 3 & 4 & 6 & 15 & 30 \\
\hline
\end{tabular}


Table 1.7: Composition of PLS in Arizona

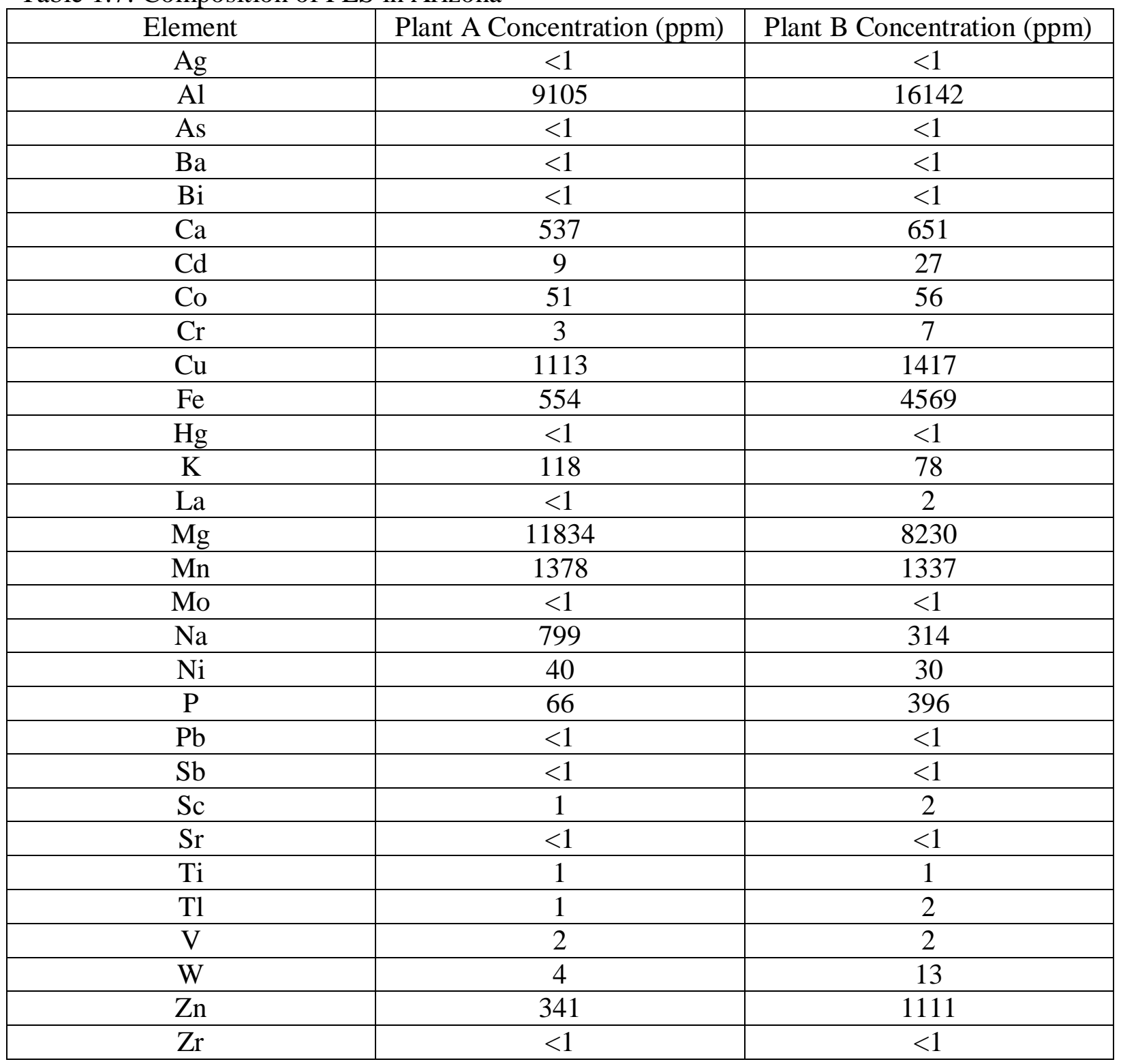




\section{CHAPTER 2: Solutions, Extraction Mechanism, and Experimental Procedure}

\subsection{RESEARCH PROJECT}

\subsubsection{Purpose}

Rare earth elements are present in leach solutions at operating copper mines. Yttrium and neodymium have been found at concentrations that could be of economic interest. The purpose of this research was to determine the feasibility of extracting yttrium and neodymium from copper PLS. Feasibility was determined by studying how a variety of parameters affected the extraction of these rare earths from the leach solution. A primary amine, Primene JM-T, was used as the extractant for these studies. The parameters that were studied included contact time, $\mathrm{pH}$ of the aqueous solution, sulfate concentration of the aqueous solutions, and extractant concentration in the organic. It was also determined how many stages it would take operationally to extract the yttrium and neodymium from the pregnant leach solutions by constructing distribution isotherms for each of the metals.

\subsubsection{Aqueous Solutions}

Synthetic yttrium and neodymium solutions as well as actual copper PLS from operating copper mines in Arizona were used for this study. A $100 \mathrm{ppm}\left(1.12 \times 10^{-3} \mathrm{M}\right)$ synthetic yttrium solution and an approximately $75 \mathrm{ppm}\left(6.93 \times 10^{-4} \mathrm{M}\right)$ synthetic neodymium solution were used

in order to study the extraction of yttrium and neodymium from pure systems. Copper PLS from Plant A in Southern Arizona was obtained in order to study the extraction from actual copper PLS from an operating copper mine. The composition of this PLS was discussed in Chapter 1 (Tables 1.6 and1.7).

\subsubsection{Organic}

The organic used for all of the experiments consisted of Primene JM-T from Dow Chemical as the extractant and kerosene from Chevron Phillips Mining Chemicals as the diluent. The standard concentration of Primene JM-T used was 0.294 M. Past research by Desouky et al. 
(2009) and others has proven that because of cost, environmental and safety factors, and the high recovery it can achieve, kerosene is the diluent of choice for the solvent extraction of rare earth elements. Primene JM-T has proven to be a good extractant for these metals. Desouky et al. (2009), Levenson et al. (1992), Rice and Stone (1962), and others have all successfully extracted rare earth elements using Primene JM-T as the extractant. Extractants, diluents, and protonation of the organic will all be discussed in the following sections.

\section{Extractant: Primene JM-T}

There are a number of requirements a chemical must meet in order for it to be able to act as a successful extractant. According to Ritcey and Ashbrook (1984), these characteristics include:

1. Relatively inexpensive

2. Low solubility in the aqueous phase

3. Good stability (be able to withstand long periods of time of recycling in a solvent extraction operation without degrading)

4, Will not form stable emulsions with aqueous when mixed

5. Good coalescing properties when mixed with diluent

6. High loading capacity

7. Easily strippable

8. Non-flammable, non-volatile, and non-toxic

9. Highly soluble in aliphatic and aromatic diluents

10. Have good extraction kinetics

In the case of this research, the chosen extractant needed to be selective toward rare earth elements, specifically yttrium and neodymium. It needed to be chemically stable under the standard experimental conditions utilized. The extractant needed to be soluble in an effective diluent and have low solubility in the synthetic solutions and copper PLS. Additionally, the extractant needed to be able to participate in a fast extraction mechanism and have a large enough capacity to hold the desired concentrations of yttrium and neodymium. Most importantly 
the extractant needed to be safe to use and not raise any environmental or health concerns. Primene JM-T met all of these requirements.

Primene-JMT (tri-alkyl-methylamine) is an aliphatic, primary amine. An amine is an organic compound related to ammonia $\left(\mathrm{NH}_{3}\right)$ except one or more of its hydrogens has been replaced by an organic group. Amines consist of hydrogen, carbon, and nitrogen. Being a primary amine means that only one hydrogen attached to the nitrogen in the original ammonia structure has been replaced by a hydrocarbon $\left(\mathrm{CH}_{x}\right)$ group resulting in a chemical formula of $\mathrm{RNH}_{2}$, where $\mathrm{R}$ is the organic group. Aliphatic simply means that Primene JM-T's carbon atoms are connected in open chains, and there are not any aromatic rings attached directly to the nitrogen atom.

Primene JM-T is a mixture of primary amines. It contains amines in the range $\mathrm{C}_{18} \mathrm{H}_{39} \mathrm{~N}$ to $\mathrm{C}_{21} \mathrm{H}_{45} \mathrm{~N}$. The most common chemical formula for Primene JM-T is $\mathrm{C}_{19} \mathrm{H}_{41} \mathrm{~N}$ which has a molecular weight of 283.61 grams per mole ("Primene JM-T" 2005). Additionally, Primene JM$\mathrm{T}$ has a specific gravity of 0.836 grams per cubic centimeter. Its structure can be seen in Figure 2.1 below ("Primene JM-T" 2005).

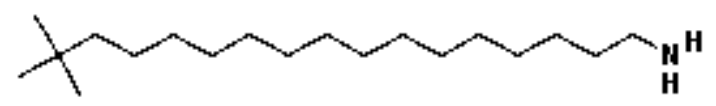

Figure 2.1: 2D Primene JM-T structure.

Primene JM-T is mainly used in applications dealing with petroleum products ("Primene JMT Amine"). This is because of its unique properties. Primene JM-T's chemical and physical properties include ("Primene JM-T Amine"):

- Resistance to oxidation

- Fluidity over wide range of temperatures

- Low viscosity over wide range of temperatures

- Color stability

- High solubility in petroleum hydrocarbons

- Anticorrosive effect 
Primene JM-T is used in the production of oil-soluble friction modifiers, it is an additive which enhances the stability of fuels, and it is utilized in fuels to maintain its fluidity and resistance to sludging during storage and heating. The petroleum industry is a consumer of Primene JM-T.

Primene JM-T has been found to be an excellent extractant for rare earth metals because of its high selectivity. Primene JM-T is considered to be a liquid anion-exchanger that requires the formation of ion-pairs or ion association to act as an extractant (Desouky et al. 2009). Prior to being used as an extractant it must be protonated in order to make an ammonia like molecule. Primene JM-T extracts negative or anionic species and complexes with sulfate when used in sulfate media. It has been proven to be a successful extractant for yttrium as well as other rare earth elements.

As with any chemical, caution should be utilized when handling and using Primene JMT. This chemical is corrosive, can cause severe eye and skin irritation, can cause burns, can be absorbed through intact skin, and can be irritating to the respiratory system ("Primene JM-T Amine"). Proper personal protective equipment including gloves should always be worn when handling this chemical. Primene JM-T should be stored at ambient temperatures. Safety is an important factor to consider when doing research with Primene JM-T, but it is definitely safe enough to use in solvent extraction experiments.

\section{Diluent: Kerosene}

The extractant is dissolved in a diluent in order to make up the organic phase. According to Ritcey and Ashbrook (1984), the reasons that a diluent is necessary are to decrease the viscosity of the extractant, to provide the correct concentration of extractant that is required for the desired conditions, to decrease emulsion-forming tendencies of the extractant, and to improve the dispersion and coalescence properties of the solvent (Ritcey and Ashbrook 1984). In order to make a successful diluent, a chemical must:

1. Be soluble with an extractant

2. Have high solvency for an extracted metal species

3. Have low volatility and a high flash point

4. Be insoluble in the aqueous phase 
5. Have a low surface tension

6. Be cheap and readily available.

When using an amine extractant such as Primene JM-T, the diluent chosen influences the extraction of metals due to the aggregation of the amine in the organic phase; aggregation can lead to a lower loading capacity of the organic (Ritcey and Ashbrook 1984). A variety of physical characteristics of the diluent determine if the amines will aggregate. The optimum diluent and extractant pair must be chosen in order to achieve the maximum extraction possible. In addition to determining that aliphatic diluents produced shorter equilibrium time and better phase separation than aromatic diluents, Desouky et al. (2009) found kerosene to be the optimum diluent for the extraction of yttrium. The results of the diluent comparison performed by Desouky et al. (2009) can be seen in Figure 2.2; the conditions used for that experiment were 0.4 M Primene-JMT, 1:1 A:O ratio, 10 minute contact time, and room temperature. Kerosene was chosen as the diluent for this research.

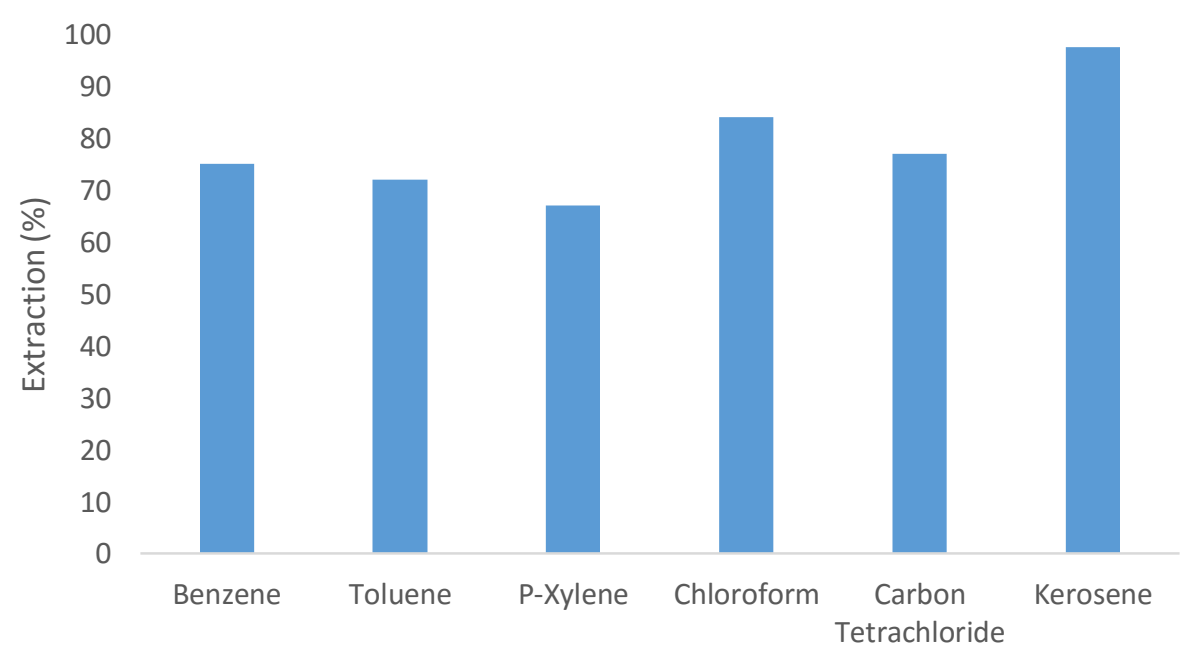

Diluent

Figure 2.2: Effect of diluent type on percent extraction. 


\section{Capacity of the Organic}

The extractant capacity for yttrium depends on which yttrium sulfate complex is being extracted. If $Y\left(\mathrm{SO}_{4}\right)_{2}^{-}$is being extracted, 1 mole of Primene JM-T is needed to extract each mole of yttrium, but if $Y\left(\mathrm{SO}_{4}\right)_{3}^{3-}$ is being extracted, 3 moles of the extractant are needed to extract each mole of yttrium. The capacities shown in Table 2.1 give a range of how much yttrium the organic can hold if a mixture of both yttrium sulfate complexes are being extracted. Using the $10 \% \mathrm{v} / \mathrm{v}$ Primene JM-T concentration as an example, Equations 2.1 and 2.2 demonstrate how the organic's capacity for $Y\left(\mathrm{SO}_{4}\right)_{2}^{-}$and $Y\left(\mathrm{SO}_{4}\right)_{3}^{3-}$, respectively, were calculated.

$$
\frac{1 \mathrm{~mol} \mathrm{Y}^{3+}}{1 \mathrm{~mol} \text { Primene }} * \frac{0.294 \mathrm{~mol} \text { Primene }}{1 \mathrm{~L}} * \frac{88.91 \mathrm{~g} \mathrm{Y^{3+ }}}{\mathrm{mol}} * \frac{1000 \mathrm{ppm}}{1 \frac{\mathrm{g}}{\mathrm{L}}}=26,140 \mathrm{ppm}
$$

$$
\frac{1 \mathrm{~mol} \mathrm{Y}^{3+}}{3 \mathrm{~mol} \text { Primene }} * \frac{0.294 \mathrm{~mol} \text { Primene }}{1 \mathrm{~L}} * \frac{88.91 \mathrm{~g} \mathrm{Y}^{3+}}{\mathrm{mol}} * \frac{1000 \mathrm{ppm}}{1 \frac{\mathrm{g}}{\mathrm{L}}}=8,713 \mathrm{ppm}
$$

Table 2.1: Capacity of the Organic at Different Extractant Concentrations

\begin{tabular}{|c|c|c|}
\hline v/v \% Concentration & {$[$ Primene JM-T] $(\mathrm{M})$} & Organic Capacity $([\bar{Y}] \mathrm{ppm})$ \\
\hline $0.25 \%$ & 0.00735 & $218-653$ \\
\hline $0.5 \%$ & 0.0147 & $436-1,307$ \\
\hline $0.75 \%$ & 0.02205 & $653-1,960$ \\
\hline $1 \%$ & 0.0294 & $871-2,614$ \\
\hline $2 \%$ & 0.0588 & $1,743-5,228$ \\
\hline $2.5 \%$ & 0.0735 & $2,178-6,535$ \\
\hline $5 \%$ & 0.147 & $4,357-13,070$ \\
\hline $10 \%$ & 0.294 & $8,713-26,140$ \\
\hline $15 \%$ & 0.441 & $13,070-39,209$ \\
\hline $20 \%$ & 0.588 & $17,426-52,279$ \\
\hline
\end{tabular}




\subsubsection{Protonating the Organic}

The extraction of the desired metal from the aqueous phase is an anion-exchange process. The metal ions must form anionic species in the aqueous phase with which the extractant, amine, can exchange an anion and perform the extraction (Ritcey and Ashbrook 1984). In order for this anion-exchange to occur the amine must first be protonated. Protonation converts the amine to an amine salt in order to provide an anion to exchange with the metal species (Ritcey and Ashbrook 1984). This exchange of anions must occur for the extraction to be successful.

The extractant, Primene JM-T, needs to be protonated to form an ammonia like molecule prior to being used in extraction tests. In order to understand this protonation, the dissociation of sulfuric acid must first be understood. Due to the dibasic character of sulfuric acid, sulfatebisulfate equilibria is present upon the dissociation of sulfuric acid (Ritcey and Ashbrook 1984). This is shown in Equations 2.3 and 2.4.

$$
\begin{gathered}
\mathrm{H}_{2} \mathrm{SO}_{4} \Leftrightarrow \mathrm{H}^{+}+\mathrm{HSO}_{4}^{-} \\
\mathrm{HSO}_{4}^{-} \Leftrightarrow \mathrm{H}^{+}+\mathrm{SO}_{4}^{2-}
\end{gathered}
$$

At high acid concentrations bisulfate is the predominate species present. This is the case at the low $\mathrm{pH}$ conditions of this research. This anionic bisulfate is necessary for the extraction of the desired metal.

Equation 2.5 shows the protonation of the Primene JM-T amine with sulfuric acid. The organic components are denoted by the line above them.

$$
\overline{\mathrm{RNH}_{2}}+\mathrm{H}_{2} \mathrm{SO}_{4} \rightarrow \overline{\mathrm{RNH}_{3} \cdot \mathrm{HSO}_{4}}
$$

This protonated form of the extractant can then come in contact with the anionic complex of the desired metal in the aqueous phase and perform the extraction. Equation 2.6 shows the extraction

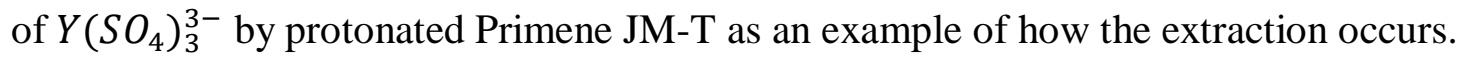

$$
\overline{3 \mathrm{RNH}_{3} \cdot \mathrm{HSO}_{4}}+\mathrm{Y}\left(\mathrm{SO}_{4}\right)_{3}^{3-} \rightarrow \overline{\left(\mathrm{RNH}_{3}\right)_{3} \mathrm{Y}\left(\mathrm{SO}_{4}\right)_{3}}+3 \mathrm{HSO}_{4}^{-}
$$


The desired metal, yttrium, goes into the organic phase, and bisulfate is released to the aqueous phase. Thus, the extractant in the organic must be protonated prior to coming in contact with the aqueous phase in order for successful extraction to occur.

\subsection{DISTRIBUTION OF SPECIES}

Yttrium can interact with sulfate to form three complexes: $\mathrm{YSO}_{4}^{+}, Y\left(\mathrm{SO}_{4}\right)_{2}^{-}$,

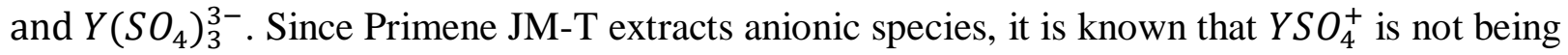
extracted. Figure 2.4 shows the distribution of the different yttrium sulfate complexes as a function of sulfate concentrations. The sulfate concentrations shown in the graph range from $0.0001 \mathrm{M}$ to $10 \mathrm{M}$. As the concentration increases to $10 \mathrm{M}$ sulfate, $Y\left(\mathrm{SO}_{4}\right)_{3}^{3-}$ becomes the predominate species. Concentrations of sulfate in copper leach solutions in Southwestern Arizona have been found to range in sulfate concentration from $0.3 \mathrm{M}$ to $1.3 \mathrm{M}$. In this range both $Y\left(\mathrm{SO}_{4}\right)_{2}^{-}$and $\mathrm{Y}\left(\mathrm{SO}_{4}\right)_{3}^{3-}$ can be present. The graph indicates that approximately $90 \%$ of the sulfate present would be in the $Y\left(\mathrm{SO}_{4}\right)_{3}^{3-}$ form while the other $10 \%$ would be $Y\left(\mathrm{SO}_{4}\right)_{2}^{-}$in a $1 \mathrm{M}$ sulfate solution. Appendix A shows the equations used to create Figure 2.3. The formation constants, $\beta_{x}$, for the yttrium sulfate complexes used for the calculations were taken from Sillen and Martell's Stability Constants of Metal-Ion Complexes (1964). These constants can be seen in Table 2.2. As one yttrium sulfate complex is extracted, the equilibrium of Equation 2.7 shifts resulting in both anionic species being extracted. Primene JM-T can extract both anionic yttrium sulfate species.

$$
Y\left(\mathrm{SO}_{4}\right)_{2}^{-}+\mathrm{SO}_{4}^{2-} \rightarrow \mathrm{Y}\left(\mathrm{SO}_{4}\right)_{3}^{3-}
$$


Table 2.2: Formation Constants for Yttrium Sulfate Complexes

\begin{tabular}{|c|c|}
\hline Complex & Formation Constant $\left(\beta_{\mathrm{x}}\right)$ \\
\hline $\mathrm{YSO}_{4}^{+}$ & 100 \\
\hline$Y\left(\mathrm{SO}_{4}\right)_{2}^{-}$ & 2,500 \\
\hline$Y\left(\mathrm{SO}_{4}\right)_{3}^{3-}$ & 23,000 \\
\hline
\end{tabular}

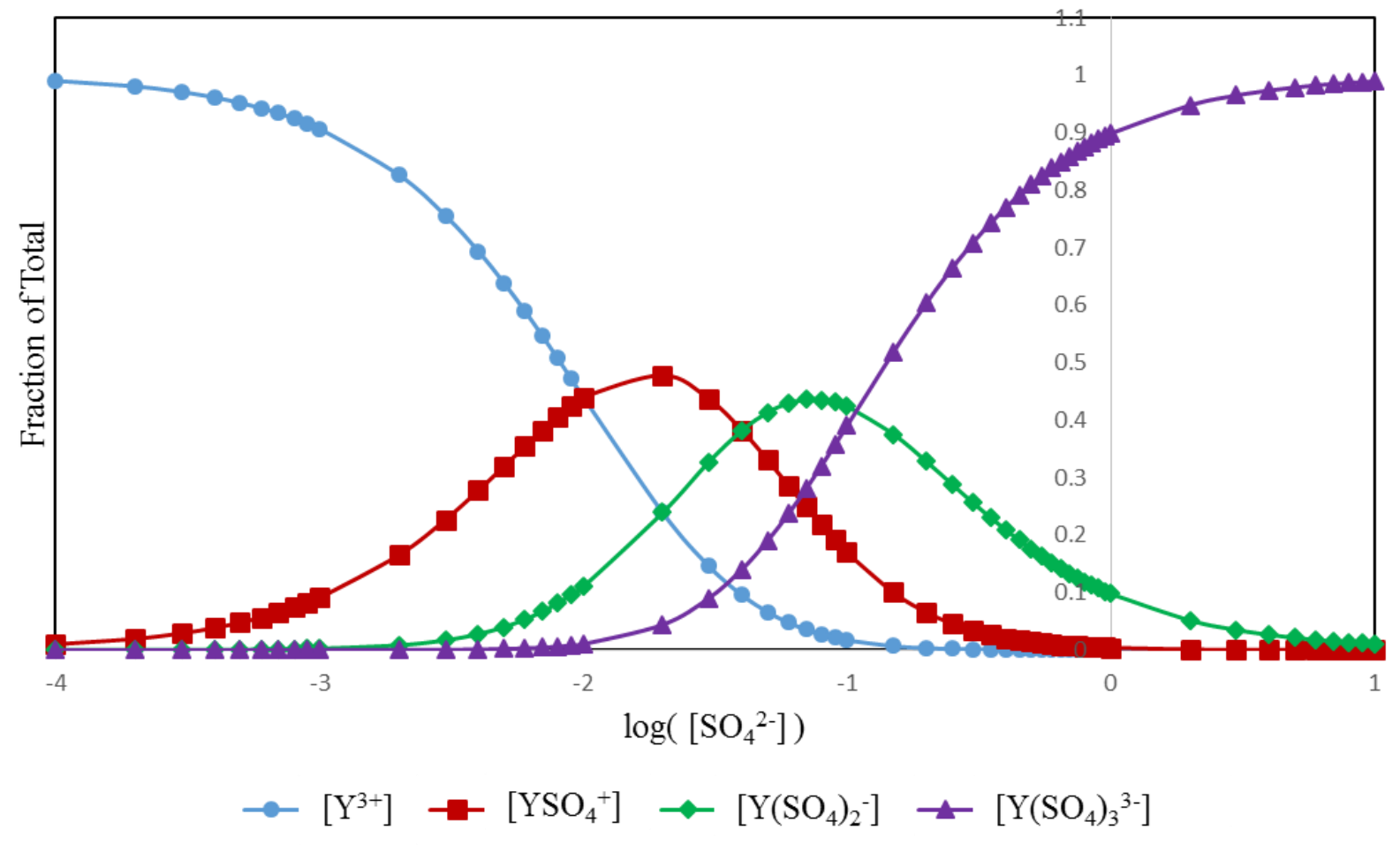

Figure 2.3: Distribution of species.

\subsection{EXTRACTION MECHANISM}

The mechanism by which Primene JM-T extracts yttrium anions from the aqueous phase is detailed here. The first step is the protonation of the amine, Primene JM-T. This protonation with sulfuric acid solutions produces sulfates or bisulfates (Nekovar and Schrotterova 2000). It is common for bisulfate to be present in the organic phase (Nekovar 1997). At low pH values, such as used in this research, bisulfate is the predominant anionic sulfate species present (Ritcey and 
Ashbrook 1984). Equation 2.8 shows the protonation of Primene JM-T and the bisulfate complex that is formed as previously discussed.

$$
\overline{\mathrm{RNH}_{2}}+\mathrm{H}_{2} \mathrm{SO}_{4} \rightarrow \overline{\mathrm{RNH}_{3} \cdot \mathrm{HSO}_{4}}
$$

Once the Primene JM-T is protonated, it can be used to extract yttrium. $\mathrm{RNH}_{3} . \mathrm{HSO}_{4}$ represents the Primene JM-T. One yttrium sulfate complex that is extracted is $\left.\mathrm{Y}_{(\mathrm{SO}}\right)_{3}^{3-}$. This is shown as Equation 2.9. Three moles of Primene JM-T are necessary to extract one mole of this yttrium sulfate complex, and 3 bisulfate ions are formed as a product.

$$
\overline{3 \mathrm{RNH}_{3} \cdot \mathrm{HSO}_{4}}+\mathrm{Y}\left(\mathrm{SO}_{4}\right)_{3}^{3-} \rightarrow \overline{\left(\mathrm{RNH}_{3}\right)_{3} \mathrm{Y}\left(\mathrm{SO}_{4}\right)_{3}}+3 \mathrm{HSO}_{4}^{-}
$$

Equation 2.10 shows the equilibrium constant of the reaction for the extraction of $Y\left(\mathrm{SO}_{4}\right)_{3}^{3-}$ shown above.

$$
K_{e q}=\frac{\overline{\left.\left(\mathrm{RNH}_{3}\right)_{3} Y\left(\mathrm{SO}_{4}\right)_{3}\right]}\left[\mathrm{HSO}_{4}^{-}\right]^{3}}{\left[\overline{\left.\mathrm{RNH}_{3} \cdot \mathrm{HSO}_{4}\right]^{3}\left[Y\left(\mathrm{SO}_{4}\right)_{3}^{3-}\right]}\right.}
$$

The distribution coefficient, D, shows how the yttrium is distributed between the organic phase and the aqueous phase (Equation 2.11). Equation 2.12 shows the substitution of the distribution coefficient into the equation for the equilibrium constant.

$$
\begin{aligned}
& D=\frac{\left[\overline{\left.\left(\mathrm{RNH}_{3}\right)_{3} Y\left(\mathrm{SO}_{4}\right)_{3}\right]}\right.}{\left.\left[\mathrm{Y}_{\mathrm{SO}}\right)_{3}^{3-}\right]} \\
& K_{e q}=\frac{D\left[\mathrm{HSO}_{4}^{-}\right]^{3}}{\left[\overline{\left.R N H_{3} . \mathrm{HSO}_{4}\right]^{3}}\right.}
\end{aligned}
$$

Taking the logarithm of both sides of Equation 2.12 results in Equation 2.13.

$$
\log K_{e q}=\log \mathrm{D}+3 \log \left[\mathrm{HSO}_{4}^{-}\right]-3 \log \left[\overline{\mathrm{RNH}_{3} \cdot \mathrm{HSO}_{4}}\right]
$$

Equation 2.13 simply rearranged is Equation 2.14. This equation provides insight into the mechanism of the reaction. The coefficient of 3 in front of the log of the Primene JM-T 
concentration indicates that 3 moles of Primene JM-T are needed to extract one mole of yttrium as was stated above. If a graph was plotted of the distribution coefficient versus the Primene JM$\mathrm{T}$ concentration on a log-log scale, the slope of the line would be 3 which would confirm that $Y\left(\mathrm{SO}_{4}\right)_{3}^{3-}$ is being extracted.

$$
\log D=3 \log \left[\overline{\mathrm{RNH}_{3} \cdot \mathrm{HSO}_{4}}\right]+\log \mathrm{K}_{\text {eq }}-3 \log \left[\mathrm{HSO}_{4}^{-}\right]
$$

With the protonated, bisulfate form of Primene JM-T another yttrium sulfate complex, $Y\left(\mathrm{SO}_{4}\right)_{2}^{-}$, can be extracted as well. In this case one mole of Primene JM-T is required to extract each mole of yttrium, and one bisulfate ion is produced. Equation 2.15 shows this reaction.

$$
\overline{\mathrm{RNH}_{3} \cdot \mathrm{HSO}_{4}}+\mathrm{Y}\left(\mathrm{SO}_{4}\right)_{2}^{-} \rightarrow \overline{\left(\mathrm{RNH}_{3}\right) \mathrm{Y}_{\left(\mathrm{SO}_{4}\right)_{2}}}+\mathrm{HSO}_{4}^{-}
$$

Equations 2.16-2.19 show the same equilibrium constant and the distribution coefficient for the extraction of $Y\left(\mathrm{SO}_{4}\right)_{2}^{-}$just like the equations above did for the extraction of the other yttrium sulfate complex.

$$
\begin{aligned}
& K_{e q}=\frac{\overline{\left[\left(\mathrm{RNH}_{3}\right) \mathrm{Y}_{\left(\mathrm{SO}_{4}\right)_{2}}\right]}\left[\mathrm{HSO}_{4}^{-}\right]}{\left[\overline{\left.\mathrm{RNH}_{3} \cdot \mathrm{HSO}_{4}\right]\left[\mathrm{Y}_{\left(\mathrm{SO}_{4}\right)_{2}^{-}}\right]}\right.} \\
& D=\frac{\left[\overline{\left(\mathrm{RNH}_{3}\right) Y\left(\mathrm{SO}_{4}\right)_{2}}\right]}{\left.\left[\mathrm{Y}_{\mathrm{SO}}\right)_{2}^{-}\right]} \\
& K_{e q}=\frac{D\left[\mathrm{HSO}_{4}^{-}\right]}{\left[\overline{\left.\mathrm{RNH}_{3} \cdot \mathrm{HSO}_{4}\right]}\right.} \\
& \log K_{e q}=\log D+\log \left[\mathrm{HSO}_{4}^{-}\right]-\log \left[\overline{\mathrm{RNH}_{3} \cdot \mathrm{HSO}_{4}}\right] \\
& \log D=\log \left[\overline{\mathrm{RNH}_{3} \cdot \mathrm{HSO}_{4}}\right]+\log \mathrm{K}_{\text {eq }}-\log \left[\mathrm{HSO}_{4}^{-}\right]
\end{aligned}
$$

Equations 2.19 and 2.20 provides insight into the mechanism of the reaction. The coefficient of 1 in front of the log of the Primene JM-T concentration indicates that 1 mole of 
Primene JM-T is needed to extract one mole of yttrium as was stated above. If a graph was plotted of the distribution coefficient versus the Primene JM-T concentration on a log-log scale, the slope of the line would be 1 which would confirm that $Y\left(S_{4}\right)_{2}^{-}$is being extracted.

\subsection{EXPERIMENTAL PROCEDURE}

Standard experimental conditions for all of the shake out tests were 5 minute contact time, $\mathrm{pH} \sim 2.5,10 \%$ v/v Primene JM-T concentration, room temperature, and 1:1 organic to aqueous phase ratio. In all of the tests $18 \mathrm{~m} \Omega$ DI water was used. Additionally, all solutions used in this research were made with AR grade chemicals. The following steps detail how the shake out tests were performed.

1. The first step for each shake out test was to prepare the aqueous solution.

In order to prepare the synthetic yttrium solution 3.43 grams of $\mathrm{Y}_{2}\left(\mathrm{SO}_{4}\right)_{3} \cdot 8 \mathrm{H}_{2} \mathrm{O}$ were mixed with $1000 \mathrm{~mL}$ of deionized (DI) water. This produced a $1000 \mathrm{ppm}(1 \mathrm{~g} / \mathrm{L}) \mathrm{yttrium}$ solution. For each shake out test $10 \mathrm{~mL}$ of this stock yttrium solution was mixed with $90 \mathrm{~mL}$ of DI water. Drops of diluted $\mathrm{H}_{2} \mathrm{SO}_{4}$ were added until the $\mathrm{pH}$ dictated by the experimental conditions was reached. For the effect of sulfate concentration test, $\mathrm{Na}_{2} \mathrm{SO}_{4}$ was added to the aqueous solution to adjust the sulfate content.

In order to prepare the synthetic neodymium solution 2 grams of $\mathrm{Nd}_{2}\left(\mathrm{SO}_{4}\right)_{3} \cdot 11 \mathrm{H}_{2} \mathrm{O}$ were mixed with $1000 \mathrm{~mL}$ of DI water. This resulted in a 1000 ppm neodymium stock solution. Like with the yttrium, $10 \mathrm{~mL}$ of this stock neodymium solution was mixed with $90 \mathrm{~mL}$ of DI water for each shake out test, and drops of diluted $\mathrm{H}_{2} \mathrm{SO}_{4}$ were added until the $\mathrm{pH}$ dictated by the experimental conditions was reached.

For the tests involving the copper mine PLS, the PLS was the aqueous phase. The PLS was used in its natural state, so no adjustments were made to it.

2. The next step in the process was to prepare the organic.

Primene JM-T was mixed with kerosene to produce the organic phase. To make the standard organic with $10 \mathrm{v} / \mathrm{v} \%$ Primene JM-T, $30 \mathrm{~mL}$ of Primene JM-T were mixed with 270 $\mathrm{mL}$ of kerosene. The organic mixture was then protonated prior to use in the shake out tests. 
In order to protonate the organic, first, $100 \mathrm{~mL}$ of $1 \mathrm{M}$ sulfuric acid was prepared by adding $6 \mathrm{~mL}$ of sulfuric acid to $94 \mathrm{~mL}$ of DI water while stirring with a stir bar on a stir plate. 50 $\mathrm{mL}$ of the $1 \mathrm{M} \mathrm{H}_{2} \mathrm{SO}_{4}$ was then placed in a $250 \mathrm{~mL}$ separatory funnel along with $150 \mathrm{~mL}$ of the prepared $10 \%$ organic. The $\mathrm{H}_{2} \mathrm{SO}_{4}$ solution and organic were shaken for 5 minutes using a Wrist Action Shaker. After shaking the solution was allowed to settle and the phases separate. Once separated the aqueous $\left(\mathrm{H}_{2} \mathrm{SO}_{4}\right)$ was discarded and the organic was then protonated and ready for use. These steps were repeated until enough protonated organic had been made.

3. Once the aqueous and organic solutions were prepared, the shake out tests could be carried out.

First, the specified volumes of the aqueous and organic solutions for the desired test were measured out and placed in a $250 \mathrm{~mL}$ separatory funnel. For the standard 1:1 O:A phase ratio, $100 \mathrm{~mL}$ of organic and $100 \mathrm{~mL}$ of aqueous were used. For the construction of the distribution isotherms the volumes of the solutions used were varied at predetermined O:A ratios.

4. The solutions in the separatory funnel were then shaken using a Wrist Action Shaker for the desired amount of time.

The standard condition required the solutions to be shaken for 5 minutes. During the kinetic test, the shaking time was varied.

5. After shaking the phases were allowed to settle and separate.

6. After the phases were separated a sample of the aqueous phase was collected for analysis. A $\mathrm{pH}$ reading of the aqueous phase was also taken.

7. The final step of each shake out test was to determine the concentration of the desired metal remaining in the aqueous phase and therefore determine how much of the metal had been extracted into the organic phase.

After each shake out test, approximately $30 \mathrm{~mL}$ of the resulting aqueous solution was taken from the separatory funnel and taken to SGS Metcon in Tucson, Arizona for analysis. At Metcon, an ICP was used to determine the concentration of the desired metal in the sample. 
From there the concentration extracted into the organic could be determined using a mass balance by knowing the feed concentration and the aqueous raffinate concentration, and then Equations 2.21 and 2.22 could be used to determine the distribution coefficient and the percent extraction, respectively, where $\mathrm{M}$ is the desired metal (yttrium or neodymium) and $\mathrm{O} / \mathrm{A}$ is the phase ratio.

$$
\begin{gathered}
D=\frac{[M]_{\text {org }}}{[M]_{a q}} \\
\% E x t=\frac{\frac{O}{A} D}{1+\frac{O}{A} D}
\end{gathered}
$$




\section{CHAPTER 3: Recovery of Yttrium and Neodymium from Synthetic Solutions}

\subsection{Kinetic Test}

The first series of experiments using $100 \mathrm{ppm}$ yttrium were performed to determine the time for the yttrium extraction reaction to reach equilibrium. Standard experimental conditions were used and contact times were varied from 1, 2, 5, 10, 15, 30, and 60 minutes. Initially, these kinetic tests were performed using organic that had not been protonated prior to use. The results indicated that the extraction of yttrium reached equilibrium in about 1 minute. Equilibrium is achieved very quickly. Desouky et al.'s (2009) research agreed with these fast kinetics. The results are shown in Table 3.1. From 1 to 60 minute contact time the extraction ranged between $76 \%$ and $81 \%$. A shake out time of 5 minutes was used as a standard condition in subsequent tests since extraction was definitely complete by that time. The effect of protonating the organic prior to each set of tests was evident in these experiments. Without protonation, yttrium extraction was $81 \%$ after 5 minutes of contact. On the other hand, with protonation of the organic, yttrium extraction was $99 \%$ after 5 minutes. All future experiments were performed with protonation of the extractant molecule. Similar results were observed for neodymium.

Table 3.1: Effect of Time on Yttrium Extraction from Synthetic Yttrium Solution

\begin{tabular}{|c|c|c|}
\hline Contact Time $(\min )$ & {$[\mathrm{Y}](\mathrm{ppm})$} & \% Extraction \\
\hline 1 & 18 & 80 \\
\hline 2 & 17 & 81 \\
\hline 5 & 17 & 77 \\
\hline 10 & 21 & 79 \\
\hline 15 & 19 & 76 \\
\hline 30 & 22 & 81 \\
\hline 60 & 17 & 81 \\
\hline
\end{tabular}




\subsection{Effect of Aqueous pH}

In the second set of experiments with the synthetic yttrium and neodymium solutions, the effect of the $\mathrm{pH}$ of the aqueous solution on the extraction was studied by using the standard experimental conditions while varying the $\mathrm{pH}$ from 0.5 to 3.5 . The results of these tests can be seen in Table 3.2 and Figure 3.1. Results were nearly identical for yttrium and neodymium. Extraction for both metals was found to be very poor at low $\mathrm{pH}$ values. At $\mathrm{pH} 0.5$ the extraction of yttrium and neodymium was only $30 \%$ and $50 \%$, respectively. This is due to the fact that there is competition between the extractable yttrium or neodymium species and $\mathrm{HSO}_{4}^{-}$(which predominates in sulfate media at low $\mathrm{pH}$ ) for the available alkyl ammonium cation at higher acid concentrations (El-Yamani and Shabana 1985).

Increasing the $\mathrm{pH}$ in this research increased the extraction. Using 0.025 M Primene JM-T in kerosene for the organic, $10^{-6} \mathrm{M}$ rare earth concentration in the aqueous, $5 \mathrm{~mL}$ of both organic and aqueous and 20 minute contact time, El-Yamani and Shabana (1985) concluded that the optimum pH range for rare earth extraction is pH 1-1.7. Desouky et al.'s (2009) research with yttrium agreed with El-Yamani and Shabana's conclusion as they found the optimum $\mathrm{pH}$ for yttrium extraction was 1.56. They achieved 97.8\% extraction at that $\mathrm{pH}$ (Desouky et al. 2009). According to Desouky et al.(2009) the above mentioned $\mathrm{pH}$ range is where the formation of an ion-pair complex in sulfate media is favorable which is why extraction is at its maximum. The research presented in this thesis is in agreement with that past research. The highest extraction achieved for both yttrium and neodymium was at $\mathrm{pH} 1.5$. At $\mathrm{pH} 1$ and higher up to $\mathrm{pH} 3.5$ the extraction ranged from $97 \%$ to $99 \%$. At $\mathrm{pH}$ values greater than 1 and up to 3.5 complete extraction occurs and is independent of $\mathrm{pH}$. Results of Levenson et al. (1992) using $10^{-3} \mathrm{M} \mathrm{Y}$, $0.5 \mathrm{M} \mathrm{Na}_{2} \mathrm{SO}_{4}$, and 5\% Primene JM-T in Escaid diluent were nearly identical to those shown here. Since the $\mathrm{pH}$ of copper PLS from operating copper mines is generally in the range of 1.5-3, the $\mathrm{pH}$ will not hinder the extraction of yttrium or neodymium from these solutions. 
Table 3.2: Effect of $\mathrm{pH}$ on Yttrium and Neodymium Extraction from Synthetic Solutions

\begin{tabular}{|c|c|c|c|c|}
\hline $\mathrm{pH}$ & {$[Y](\mathrm{ppm})$} & $Y \%$ Extraction & {$[N d](\mathrm{ppm})$} & $N d \%$ Extraction \\
\hline 0.5 & 70 & 30 & 42 & 50 \\
\hline 1 & 1 & 99 & 3 & 96 \\
\hline 1.5 & 1 & 99 & 1 & 99 \\
\hline 2 & 2 & 98 & 1 & 99 \\
\hline 2.5 & 3 & 97 & 1 & 99 \\
\hline 3 & 2 & 98 & 1 & 99 \\
\hline 3.5 & 2 & 98 & 1 & 99 \\
\hline
\end{tabular}

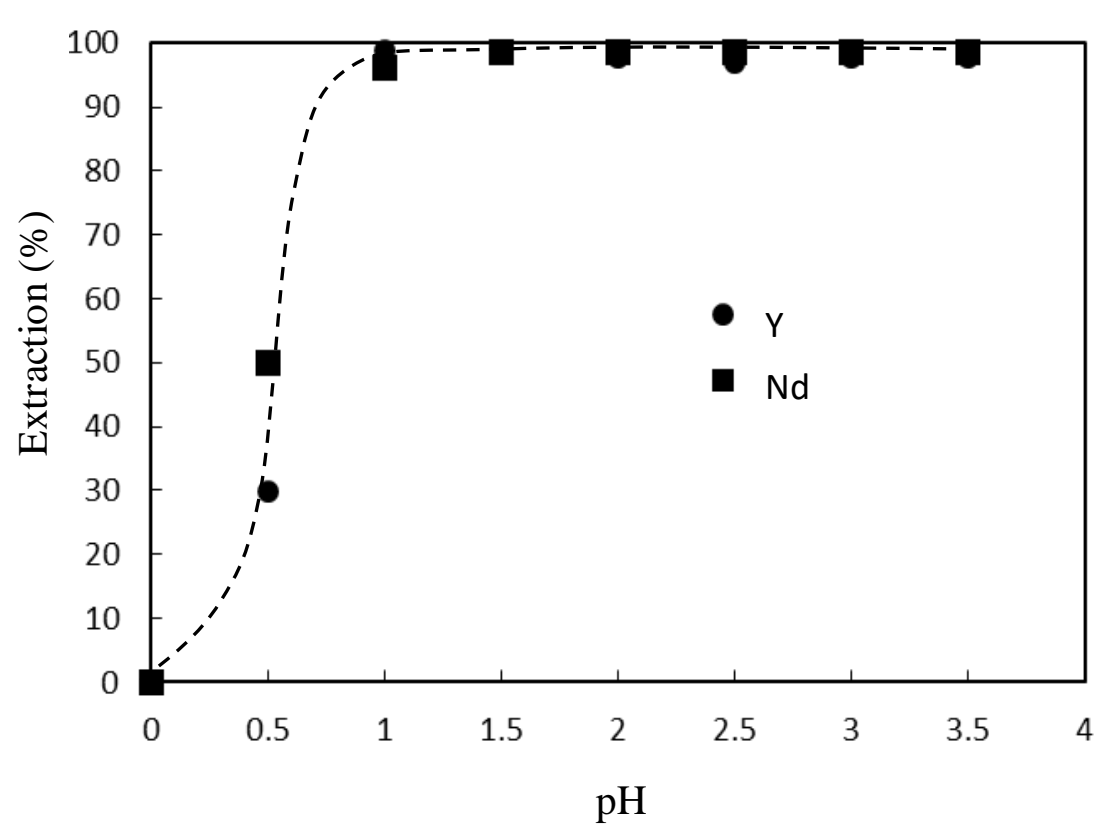

Figure 3.1: Percent extraction of yttrium and neodymium from synthetic solutions as a function of $\mathrm{pH}$.

After each shake out test, a sample was taken of the raffinate after the phases had separated, and a $\mathrm{pH}$ reading was taken of that solution. The $\mathrm{pH}$ of the raffinate was usually lower than the $\mathrm{pH}$ of the original aqueous feed. As was shown in Equations 2.9 and 2.15, when the extractant reactions with the yttrium sulfate, bisulfate is produced in the aqueous phase. Equation 2.4 showed that bisulfate can decompose to produce hydrogen and sulfate. This hydrogen that is produced is now in the aqueous phase which results in the $\mathrm{pH}$ of the raffinate being lower than the $\mathrm{pH}$ of the aqueous feed. 


\subsection{Effect of Aqueous Sulfate Concentration}

Actual copper leach solutions can vary widely with respect to total sulfate concentration. Sulfate concentrations ranging from $0.3 \mathrm{M}$ to $1.3 \mathrm{M}$ have been measured for leaching operations in the Southwestern United States. The effect of sulfate concentration in the aqueous phase on the extraction was studied using the synthetic yttrium solution. The sulfate concentration was changed by adding sodium sulfate, $\mathrm{Na}_{2} \mathrm{SO}_{4}$, to the aqueous phase. The sulfate concentrations ranged from $0.01-1.0 \mathrm{M} \mathrm{SO}_{4}{ }^{2-}$. The results of these experiments are provided in Table 3.3. As can be seen, the extraction of yttrium is practically complete at all sulfate concentrations tested and can be considered essentially independent of sulfate concentration. Copper PLS can be high in sulfate concentration without adversely affecting the extraction of yttrium.

Table 3.3: Effect of Sulfate Concentration on Yttrium Extraction from Synthetic Yttrium Solution

\begin{tabular}{|c|c|c|}
\hline$\left[\mathrm{SO}_{4}{ }^{2-}\right](\mathrm{M})$ & {$[Y](\mathrm{ppm})$} & \% Extraction \\
\hline 0.01 & 3 & 97 \\
\hline 0.05 & 2 & 98 \\
\hline 0.1 & 7 & 93 \\
\hline 0.5 & 1 & 99 \\
\hline 1.0 & 4 & 96 \\
\hline
\end{tabular}

Since rare earth elements all have like chemical and physical properties, the stability constants of lanthanide sulfates are all similar in value. Yttrium and neodymium have comparable stability constants. Carvalho and Choppin (1967) provide $\beta_{1}$ and $\beta_{2}$ values for neodymium and yttrium. $\beta_{1}$ for yttrium is $17.2+/-2.8$ and $\beta_{2}$ for yttrium is shown to be $48+/-7$ while $\beta_{1}$ for neodymium is $18.1+/-2.4$ and $\beta_{2}$ for neodymium has a value of $62+/-9$. Since yttrium and neodymium have stability constants that are similar, it can be assumed that neodymium extraction will be independent of sulfate concentration like yttrium extraction has proven to be. Thermodynamic data for yttrium and neodymium also confirms this claim. Carvalho and Choppin (1967) determined thermodynamic parameters for the formation of lanthanide sulfate complexes. The Gibbs standard free energy, $\Delta \mathrm{G}^{\circ}$, of the formation of $\mathrm{YSO}_{4}^{+}$is $1.68 \mathrm{kcal} / \mathrm{mole}$ while the $\Delta \mathrm{G}^{\circ}$ of the formation of $N_{S S O_{4}^{+}}$is $1.71 \mathrm{kcal} / \mathrm{mole}$, and the $\Delta \mathrm{G}^{\circ}$ of the formation of $Y\left(\mathrm{SO}_{4}\right)_{2}^{-}$is $0.61 \mathrm{kcal} / \mathrm{mole}$ while the value for $\mathrm{Nd}\left(\mathrm{SO}_{4}\right)_{2}^{-} 0.72$ (Carvalho and 
Choppin 1967). The NBS Tables of Chemical Thermodynamic Properties also give values for the thermodynamic properties of these yttrium and neodymium sulfate complexes that are similar to each other (Wagman et al. 1982). Gibbs standard free energy of reaction values can be used to calculate the equilibrium constants for the reactions which are equal to the formation constants. This helps to show that yttrium and neodymium have similar formation constants. Because of this, the effect of sulfate concentration on neodymium extraction would draw the same conclusion as the yttrium sulfate test did; the sulfate concentration will not inhibit yttrium or neodymium extraction from copper leach solutions.

\subsection{Effect of Extractant Concentration}

The effect of Primene JM-T concentration in the organic phase on the extraction of yttrium and neodymium was studied in the range of $0.00735 \mathrm{M}-0.588 \mathrm{M}(0.25$ to $20 \mathrm{v} / \mathrm{v} \%)$ for yttrium and $(0.0147 \mathrm{M}-0.588 \mathrm{M}(0.5$ to $20 \mathrm{v} / \mathrm{v} \%)$ for neodymium. Table 3.4 shows the results for yttrium. Practically complete extraction of yttrium occurred at every concentration level except for with $0.25 \% \mathrm{v} / \mathrm{v}(0.00735 \mathrm{M})$ Primene JM-T concentration. Only $49 \%$ recovery was achieved at that concentration. Increasing Primene JM-T concentration up to $2 \%$ increased the extraction to $99 \%$ after which it essentially plateaued. Figure 3.2 shows the effect of extractant concentration on recovery. The insert in Figure 3.2 provides more detail for the low Primene JM$\mathrm{T}$ region before the recovery plateaued.

Table 3.4: Effect of Extractant Concentration on Yttrium Extraction from Synthetic Yttrium Solution

\begin{tabular}{|c|c|c|c|c|c|c|c|}
\hline & $\begin{array}{c}{[\text { Primene }} \\
\text { JM-T }](\mathrm{M})\end{array}$ & $\begin{array}{c}{[Y]} \\
(\mathrm{ppm})\end{array}$ & $\begin{array}{c}{[\bar{Y}]} \\
(\mathrm{ppm})\end{array}$ & $\mathrm{D}$ & $\log (\mathrm{D})$ & $\begin{array}{c}\text { Log }([\text { Primene } \\
\mathrm{JM}-\mathrm{T}])\end{array}$ & $\begin{array}{c}\text { Extraction } \\
\%\end{array}$ \\
\hline $0.25 \%$ & 0.00735 & 51 & 49 & 0.96 & -0.017 & -2.134 & 49 \\
\hline $0.5 \%$ & 0.0147 & 10 & 90 & 9 & 0.954 & -1.833 & 90 \\
\hline $0.75 \%$ & 0.02205 & 6 & 94 & 15.67 & 1.195 & -1.657 & 94 \\
\hline $1 \%$ & 0.0294 & 4 & 96 & 24 & 1.380 & -1.532 & 96 \\
\hline $2 \%$ & 0.0588 & 1 & 99 & 99 & 1.996 & -1.231 & 99 \\
\hline $2.5 \%$ & 0.0735 & 1 & 99 & 99 & 1.996 & -1.134 & 99 \\
\hline $5 \%$ & 0.147 & 1 & 99 & 99 & 1.996 & -0.833 & 99 \\
\hline $10 \%$ & 0.294 & 2 & 98 & 49 & 1.690 & -0.532 & 98 \\
\hline $15 \%$ & 0.441 & 2 & 98 & 49 & 1.690 & -0.356 & 98 \\
\hline $20 \%$ & 0.588 & 3 & 97 & 32.3 & 1.510 & -0.231 & 97 \\
\hline
\end{tabular}




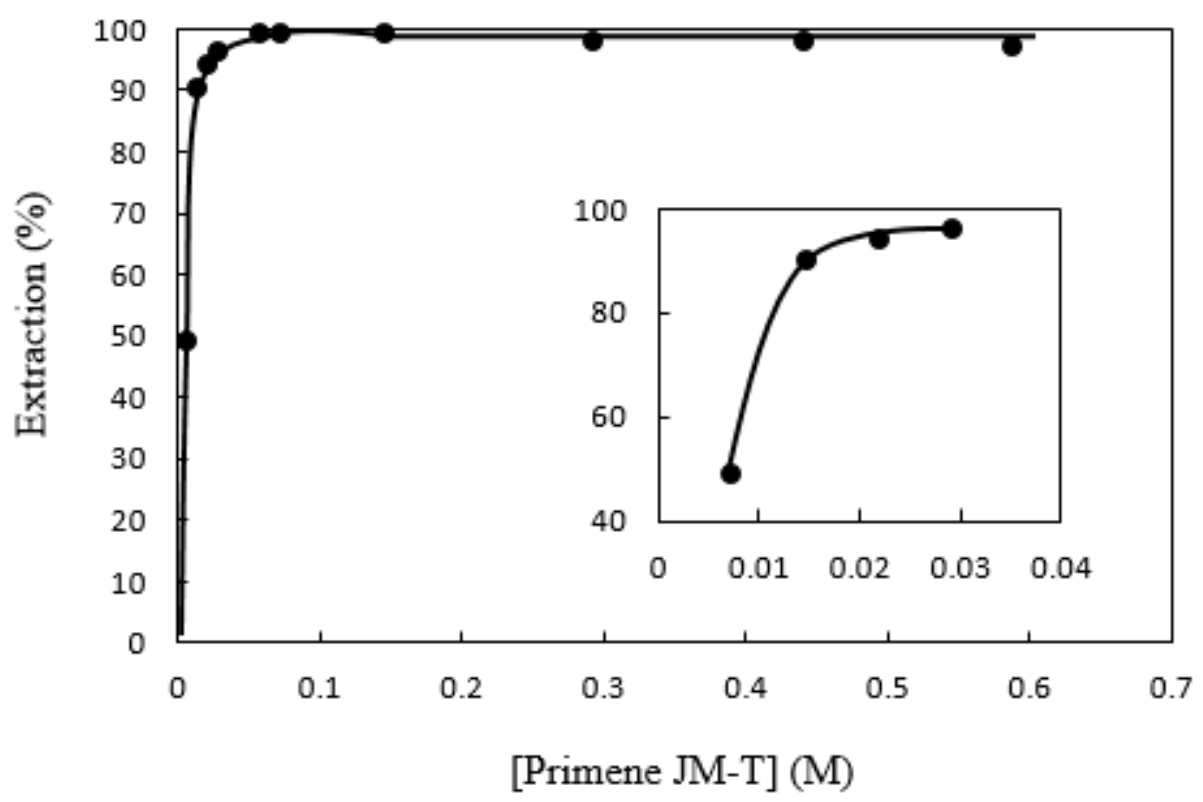

Figure 3.2: Percent extraction of yttrium from synthetic yttrium solution as a function of Primene JM-T concentration.

Plotting the distribution coefficient, D, versus the Primene JM-T concentration on a log$\log$ plot is shown in Figure 3.3 for the pre-plateau region of Figure 3.2. This plot shows a slope of approximately 2.This gives insight into how many moles of Primene JM-T are required to extract each mole of yttrium. Since it was shown in Chapter 2 Equations 2.13 and 2.19 that the extraction of $Y\left(\mathrm{SO}_{4}\right)_{3}^{3-}$ requires 3 moles of extractant per mole of yttrium and $Y\left(\mathrm{SO}_{4}\right)_{2}^{-}$requires 1 mole of extractant per mole of yttrium, the slope of 2 in Figure 3.3 indicates that both yttrium sulfate complexes are being extracted. The species distribution discussed in Chapter 2 shows that this is possible. Varying the extractant concentration helps explain the extraction mechanism. 


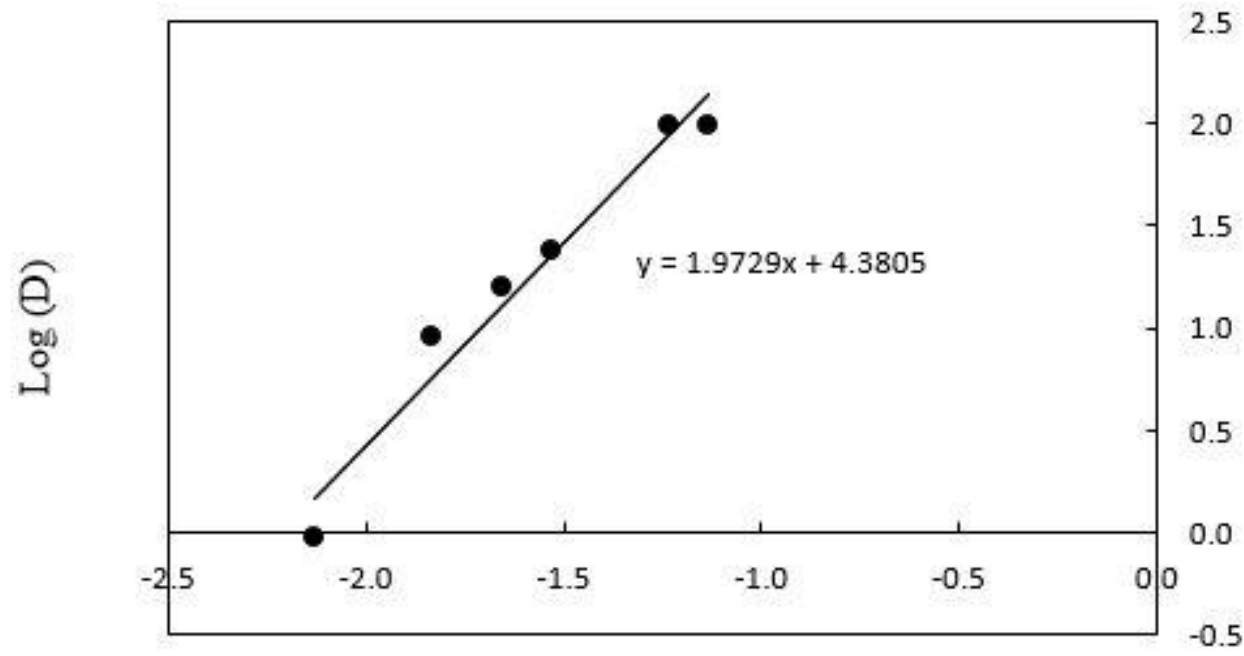

$\log ([$ Primene JM-T])

Figure 3.3: Distribution coefficient as a function of Primene JM-T concentration using synthetic yttrium solution.

The same experiment was run with neodymium, and practically complete ( $99 \%)$ extraction of neodymium was achieved for every Primene JM-T concentration. Therefore it was concluded that neodymium extraction is independent of extractant concentration in the $0.0147 \mathrm{M}$ $-0.588 \mathrm{M}$ range.

\subsection{Distribution Isotherms}

A distribution isotherm for the extraction of yttrium using the synthetic yttrium solution was generated. The isotherm was created by using the standard experimental conditions and varying the organic to aqueous phase ratio. O:A phase ratios tested included 1:1, 1:2, 1:3, 1:4, $1: 5$, and 1:10. Concentration of yttrium in the aqueous phase was determined analytically, and then yttrium in the organic was calculated using a mass balance as shown in Equation 3.1, where $\mathrm{A}$ and $\mathrm{O}$ represent the aqueous and organic portions, respectively.

$$
[Y]_{\text {Feed }} A=[Y]_{\text {Raffinate }} A+[\bar{Y}]_{\text {organic }} O
$$


The isotherm produced can be seen in Figure 3.4. At the normal 1:1 O:A phase ratio, 99\% of the yttrium was extracted. As the aqueous portion increased from 1 to 10 the recovery slowly decreased from $99 \%$ to $89 \%$. Results including percent extraction can be seen in Table 3.5. This is in agreement with what Desouky et al.(2009) found in their research. The isotherm shows that the extraction of yttrium at these conditions can operationally take place in one stage.

Table 3.5: Distribution Isotherm Results Using Synthetic Yttrium Solution

\begin{tabular}{|c|c|c|c|}
\hline O:A & {$[Y](\mathrm{ppm})$} & {$[\bar{Y}](\mathrm{ppm})$} & \% Extraction \\
\hline $1: 1$ & 1 & 99 & 99 \\
\hline $1: 2$ & 2 & 196 & 98 \\
\hline $1: 3$ & 3 & 291 & 97 \\
\hline $1: 4$ & 4 & 384 & 96 \\
\hline $1: 5$ & 4 & 480 & 96 \\
\hline $1: 10$ & 11 & 890 & 89 \\
\hline
\end{tabular}

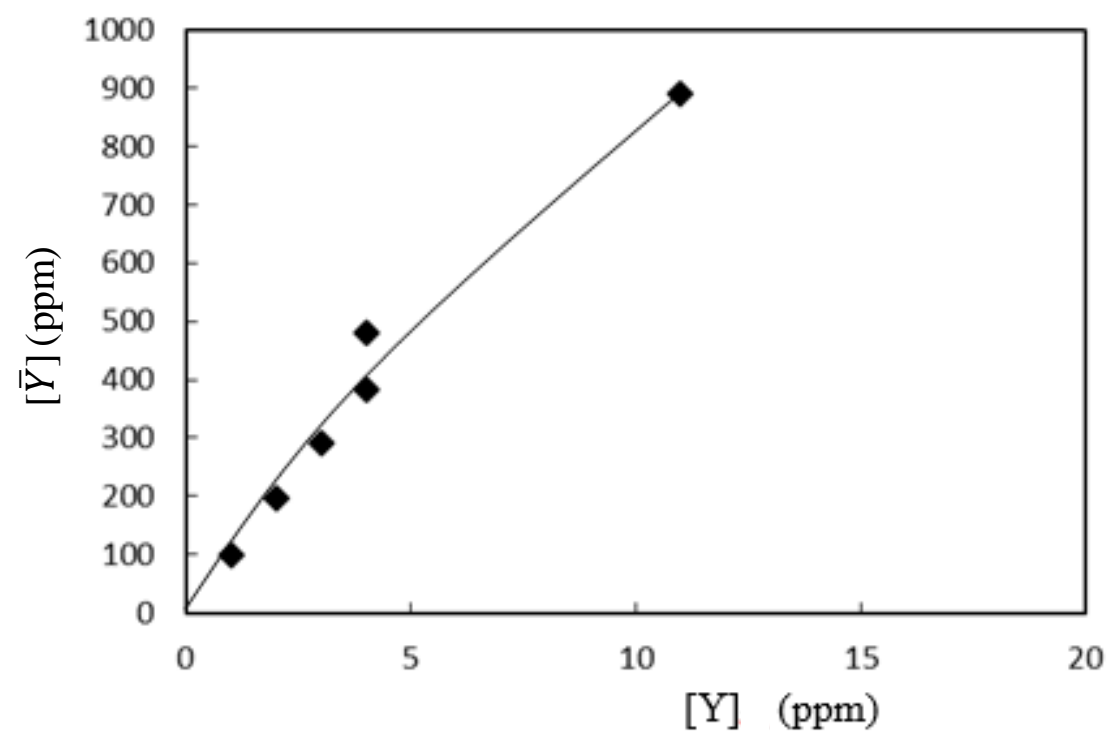

Figure 3.4: Distribution isotherm using synthetic yttrium solution. 
During Desouky et al.'s (2009) study of yttrium extraction, a distribution isotherm was created. That research utilized an $8.86 \times 10^{-3} \mathrm{M}(788 \mathrm{ppm})$ yttrium solution as its feed (Desouky et al. 2009). That is about 8 times higher than the yttrium concentration $\left(1.12 \times 10^{-3} \mathrm{M}\right.$ or 100 ppm) used in this research. Using the organic to aqueous phase ratios and respective distribution coefficients, the isotherm produced by Desouky et al. (2009) was reconstructed and plotted with the isotherm shown above in Figure 3.4. This comparison can be seen in Figure 3.5. The blue line with the diamond markers represents the isotherm generated from this research at low yttrium concentrations while the red line with square markers represents Desouky et al.'s (2009) isotherm at high yttrium concentrations.

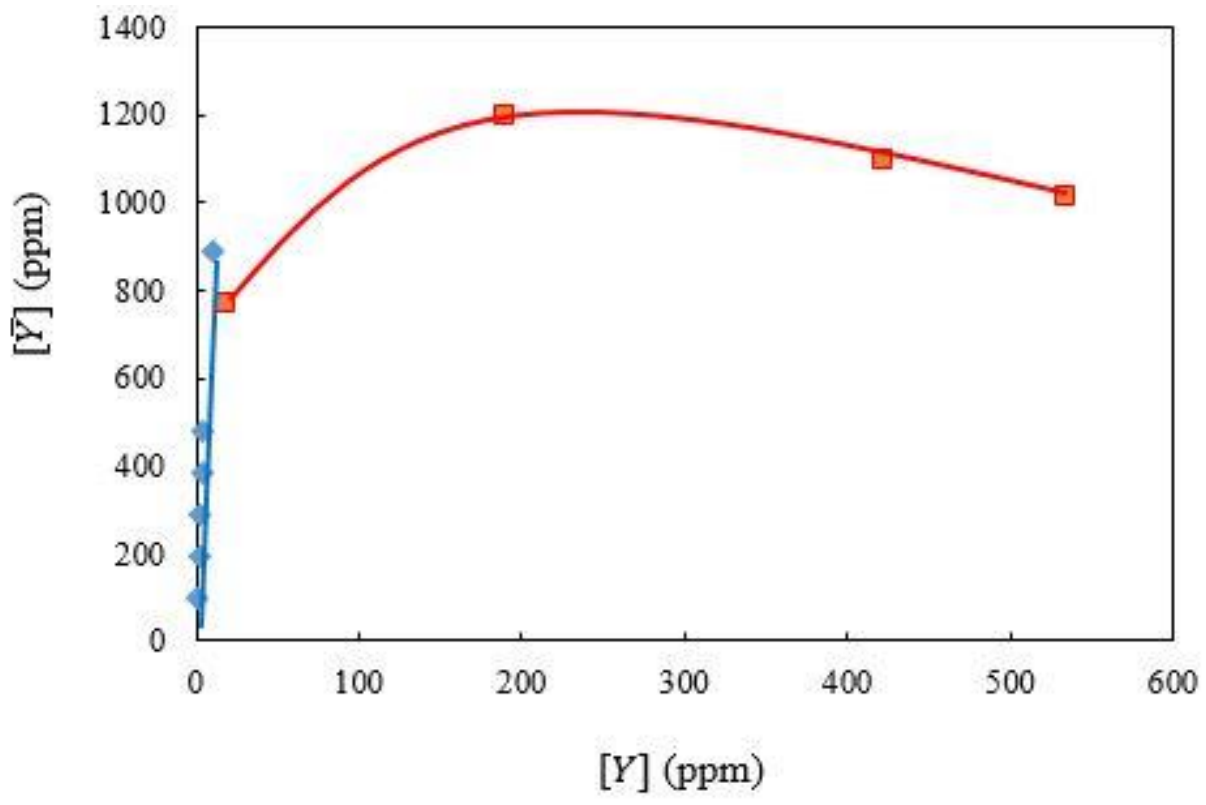

Figure 3.5: High and low yttrium concentration distribution isotherm comparison using synthetic solutions.

A distribution isotherm for synthetic solutions of neodymium was also generated. Under the same conditions, the results for neodymium were similar to those for yttrium. These results and isotherm are shown in Table 3.6 and Figure 3.6. Practically complete extraction was achieved with every phase ratio. Extraction of neodymium can also operationally take place in one stage at this low concentration. 
Table 3.6: Distribution Isotherm Results Using Synthetic Neodymium Solution

\begin{tabular}{|c|c|c|c|}
\hline O:A & {$[N d](\mathrm{ppm})$} & {$[\overline{N d}](\mathrm{ppm})$} & \% Extraction \\
\hline $1: 1$ & 1 & 81 & 99 \\
\hline $1: 2$ & 1 & 162 & 99 \\
\hline $1: 3$ & 1 & 243 & 99 \\
\hline $1: 4$ & 1 & 324 & 99 \\
\hline $1: 5$ & 2 & 400 & 98 \\
\hline $1: 10$ & 3 & 790 & 96 \\
\hline
\end{tabular}

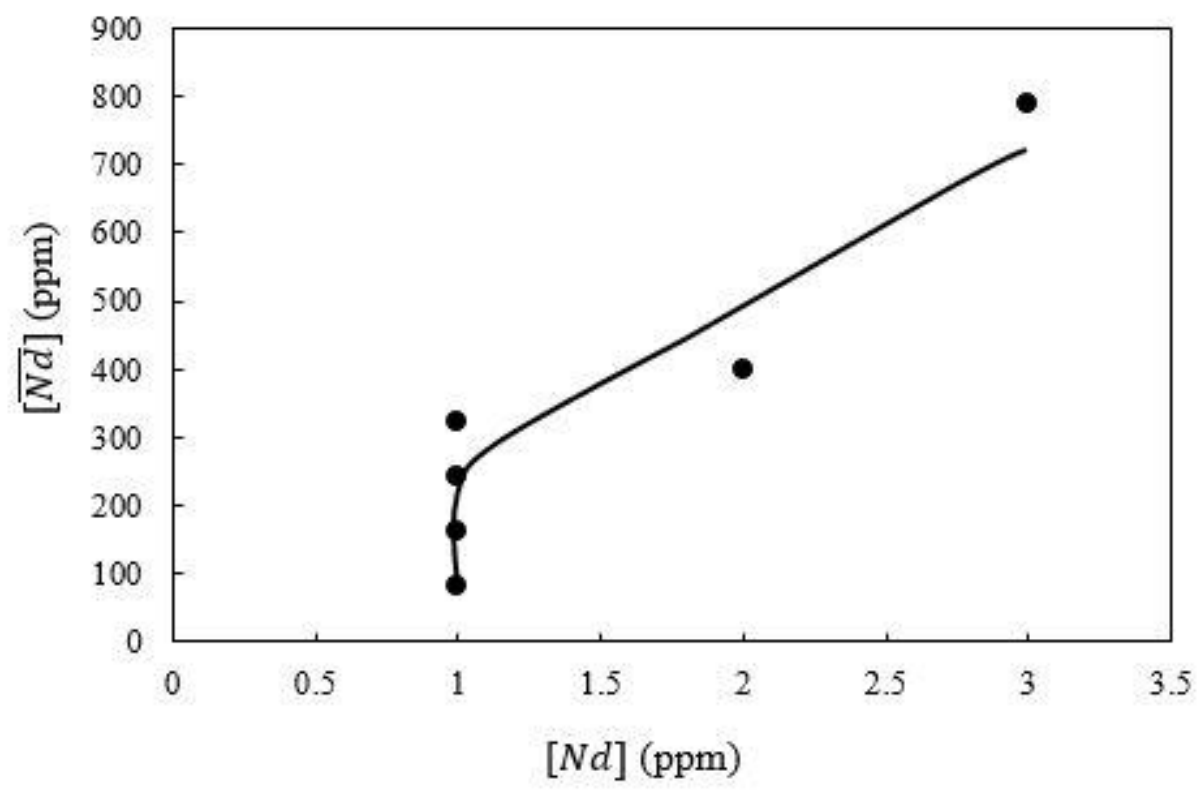

Figure 3.6: Distribution isotherm using synthetic neodymium solution.

Throughout all of the tests with the synthetic yttrium solution, it was found that while using the standard experimental conditions practically all of the yttrium was recovered in each test. The capacity of the organic (discussed in Chapter 2) was never reached. Because of this, it was decided to test multiple contacts of the organic with fresh aqueous feed each time. For this test an organic to aqueous ratio of 1:2 was used along with 5\% v/v extractant concentration in the organic. Standard conditions of $\mathrm{pH} \sim 2.5,5$ minute contact time, and room temperature were still maintained. For this test, the same organic was contacted with fresh aqueous feed four times. Results can be seen in Table 3.7. The isotherm created is shown in Figure 3.7 compared to the 
isotherm created from single contacts. The single contact isotherm is shown with the closed square markers and the solid line while the isotherm of multiple contacts is represented with the open square markers and the dashed line. The organic was successfully able to continue to extract yttrium up to four contacts with fresh feed.

Table 3.7: Distribution Isotherm with Multiple Contacts Using Synthetic Yttrium Solution

\begin{tabular}{|c|c|c|}
\hline Contact & {$[Y](\mathrm{ppm})$} & {$[\bar{Y}](\mathrm{ppm})$} \\
\hline 1 & 2 & 196 \\
\hline 2 & 6 & 384 \\
\hline 3 & 14 & 556 \\
\hline 4 & 24 & 708 \\
\hline
\end{tabular}

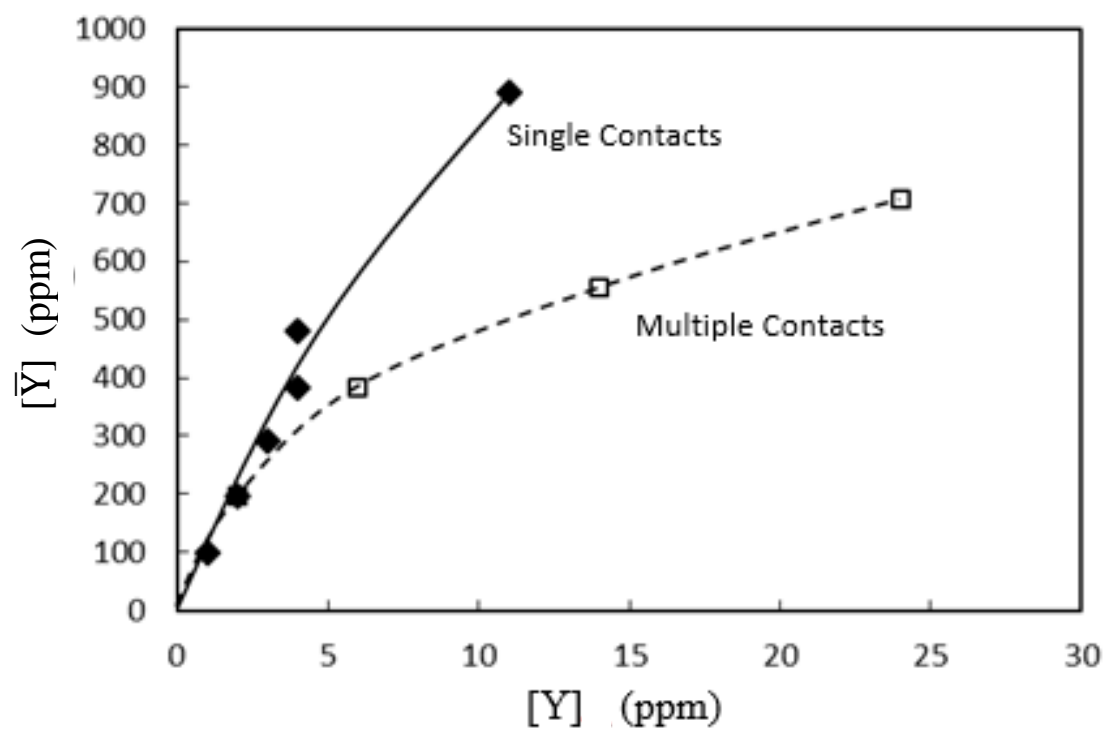

Figure 3.7: Single contact vs. multiple contacts using synthetic yttrium solution. 


\section{CHAPTER 4: Recovery of Yttrium and Neodymium from Copper PLS}

After studying the extraction of yttrium and neodymium from synthetic solutions, extraction from actual copper PLS was studied. A PLS sample for study was collected from Plant A. The effect of extractant, Primene JM-T, concentration was tested on the recovery of these metals from the PLS. Additionally, distribution isotherms were constructed for both yttrium and neodymium. These tests were run at standard conditions and the natural $\mathrm{pH}$ of the PLS, 1.86.

\subsection{PLS Composition}

The PLS from Plant A was tested in its natural state. Table 1.6 in Chapter 1 shows the composition of the rare earth elements that are present in the PLS. Neodymium is present at a concentration of $2.1 \mathrm{ppm}$, and yttrium is present at a concentration of $14.9 \mathrm{ppm}$. The other rare earths, cerium, lanthanum, praseodymium, samarium, thorium, and uranium, are only present at the very low concentrations of $1 \mathrm{ppm}$ or less than one ppm. Plant A PLS is a proven source of yttrium and neodymium.

Table 1.7 in Chapter 1 shows the complete composition of the Plant A PLS. Copper is present in the pregnant leach solution at Plant A at the concentration of $1113 \mathrm{ppm}$. Other notable constituents of the PLS include aluminum and iron. Aluminum concentration is $9105 \mathrm{ppm}$ and iron concentration is $554 \mathrm{ppm}$. These concentrations are noteworthy because when doing solvent

extraction, it is possible for the $\mathrm{Al}^{3+}$ or $\mathrm{Fe}^{3+}$ ions to form anionic complexes with the sulfate and take up space on the organic thus hindering the ability to extract the low concentrations of yttrium and neodymium. This PLS also has high levels of magnesium and manganese. Additionally, Plant A PLS contains $34.5 \mathrm{~g} / \mathrm{l}$ (34,500 ppm) of sulfur and has a pH of 1.86.

\subsection{Distribution Isotherms}

Distribution isotherms for the recovery of yttrium and neodymium from copper PLS were created by varying the organic to aqueous phase ratios. For both metals extraction was achieved at all O:A ratios. Table 4.1 shows the conditions for the isotherm tests and the percent extraction achieved for each metal under each condition. An O:A ratio of 4:1 achieved the highest 
extraction of each metal: close to $100 \%$ for yttrium and $98 \%$ for neodymium. Percent extraction decreased as the aqueous portion increased. The lowest recovery occurred with the 1:4 O:A ratio. At the 1:4 ratio only $38 \%$ extraction was achieved for yttrium and $67 \%$ extraction for neodymium. Given this information, isotherms were constructed.

Table 4.1: Yttrium and Neodymium Distribution Isotherms Using PLS

\begin{tabular}{|c|c|c|c|c|c|c|c|c|}
\hline \multirow{2}{*}{ PLS } & \multirow{2}{*}{$\mathrm{pH}$} & O/A & \multicolumn{3}{|c|}{ Yttrium } & \multicolumn{3}{|c|}{ Neodymium } \\
\cline { 3 - 8 } & $\begin{array}{c}\text { Feed } \\
(\mathrm{ppm})\end{array}$ & $\begin{array}{c}\text { Raffinate* } \\
(\mathrm{ppm})\end{array}$ & $\%$ Ext & $\begin{array}{c}\text { Feed } \\
(\mathrm{ppm})\end{array}$ & $\begin{array}{c}\text { Raffinate* } \\
(\mathrm{ppm})\end{array}$ & $\%$ Ext \\
\hline \multirow{4}{*}{ Plant } & & $4: 1$ & 14.9 & $<0.1$ & $\sim 100$ & 2.1 & $<0.1$ & 98 \\
A & \multirow{2}{*}{1.86} & $2: 1$ & 14.9 & 0.8 & 95 & 2.1 & $<0.1$ & 98 \\
& & $1: 1$ & 14.9 & 1.47 & 90 & 2.1 & 0.1 & 95 \\
& $1: 2$ & 14.9 & 3 & 80 & 2.1 & 0.2 & 90 \\
\hline
\end{tabular}

* Raffinate values less than $0.1 \mathrm{ppm}$ are assumed to be $\sim 0.05 \mathrm{ppm}$.

The distribution isotherm for yttrium is shown in Figure 4.1, and the isotherm for neodymium is shown in Figure 4.2. These isotherms show that at these low concentrations both yttrium and neodymium can be operationally extracted in one stage. This means only one mixer and one settler would be needed at an operation to extract the maximum of these metals from the copper leach solution. 


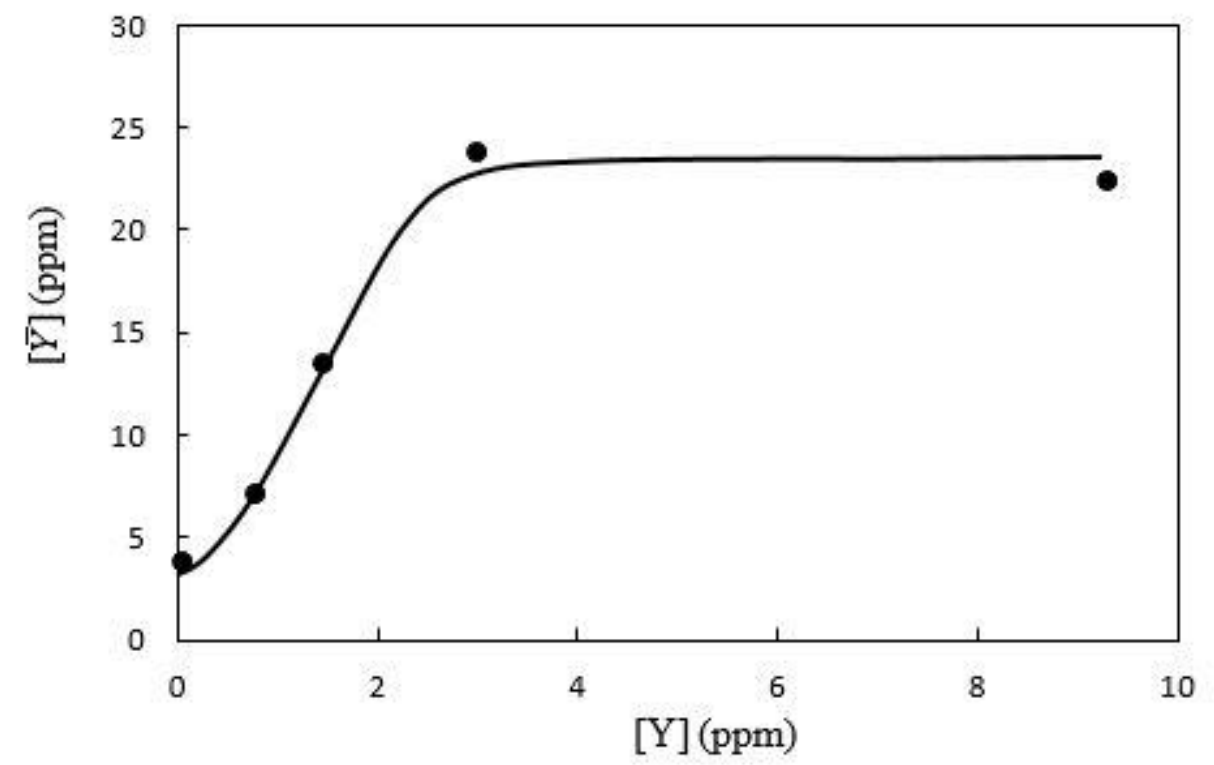

Figure 4.1: Yttrium distribution isotherm using PLS.

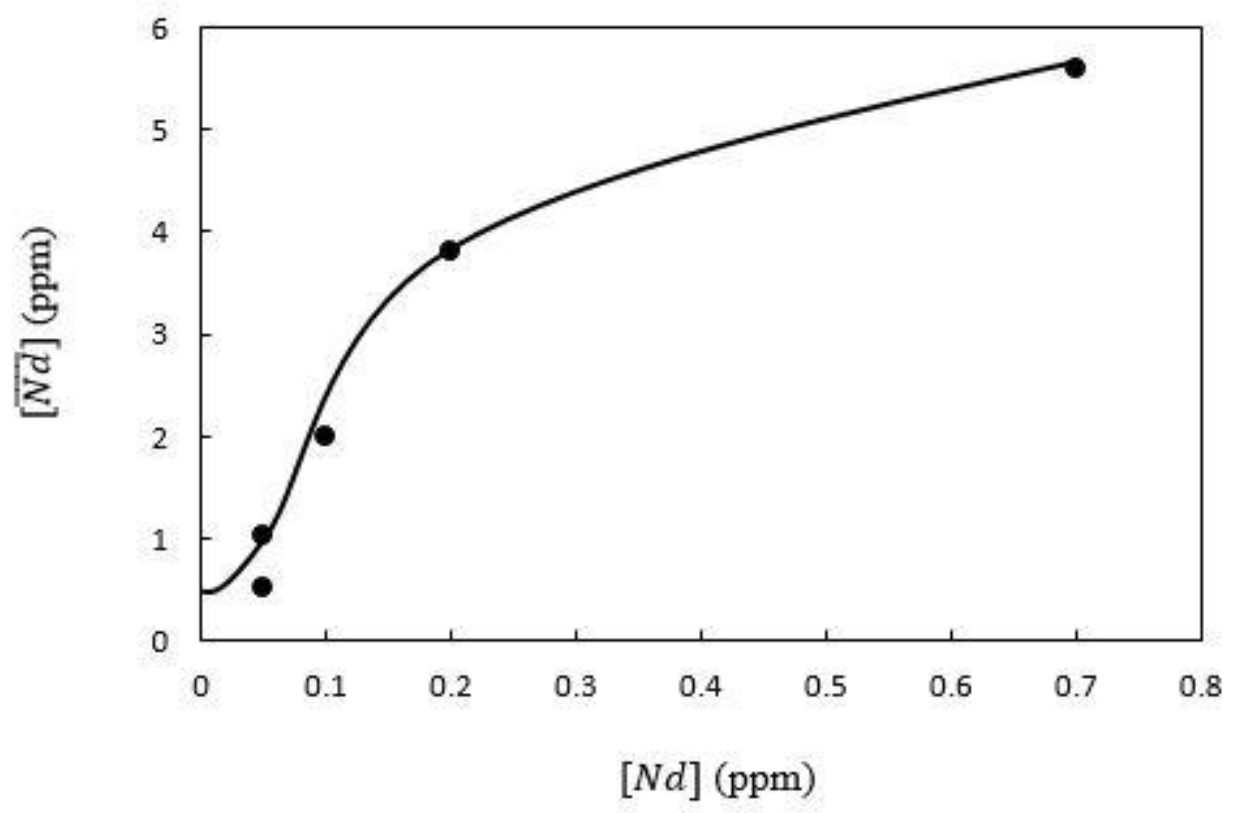

Figure 4.2: Neodymium distribution isotherm using PLS. 


\subsection{Effect of Extractant Concentration}

The effect of extractant concentration on the extraction of yttrium and neodymium from copper PLS was also studied. The extractant concentration was studied in the range of $0.0294 \mathrm{M}$ to $0.294 \mathrm{M}$. Table 4.2 shows the results for yttrium. No extraction was achieved with a $1 \% \mathrm{v} / \mathrm{v}$ Primene JM-T concentration. Figure 4.3 shows the effect of the extractant concentration on the extraction. From 2.5\% (0.0735 M) to 10\% (0.294 M) Primene JM-T, the extraction increased up to $90 \%$. Extractant concentration tests were all carried out at the standard 1:1 organic to aqueous phase ratio.

Table 4.2: Yttrium Effect of Extractant Concentration Using PLS

\begin{tabular}{|c|c|c|c|c|c|c|c|}
\hline & $\begin{array}{c}{[\text { Primene }} \\
\mathrm{JM}-\mathrm{T}](\mathrm{M})\end{array}$ & $\begin{array}{c}{[Y]} \\
(\mathrm{ppm})\end{array}$ & $\begin{array}{c}{[\bar{Y}]} \\
(\mathrm{ppm})\end{array}$ & $\mathrm{D}$ & $\begin{array}{c}\text { Log } \\
(\mathrm{D})\end{array}$ & $\begin{array}{c}\text { Log ([Primene } \\
\mathrm{JM}-\mathrm{T}])\end{array}$ & $\begin{array}{c}\text { Extraction } \\
(\%)\end{array}$ \\
\hline $1 \%$ & 0.0294 & 14.9 & 0 & - & - & -1.532 & - \\
\hline $2.5 \%$ & 0.0735 & 9.7 & 5.2 & 0.54 & -0.271 & -1.134 & 35 \\
\hline $5 \%$ & 0.147 & 2.2 & 12.7 & 5.77 & 0.761 & -0.833 & 85 \\
\hline $10 \%$ & 0.294 & 1.47 & 13.43 & 9.14 & 0.961 & -0.532 & 90 \\
\hline
\end{tabular}




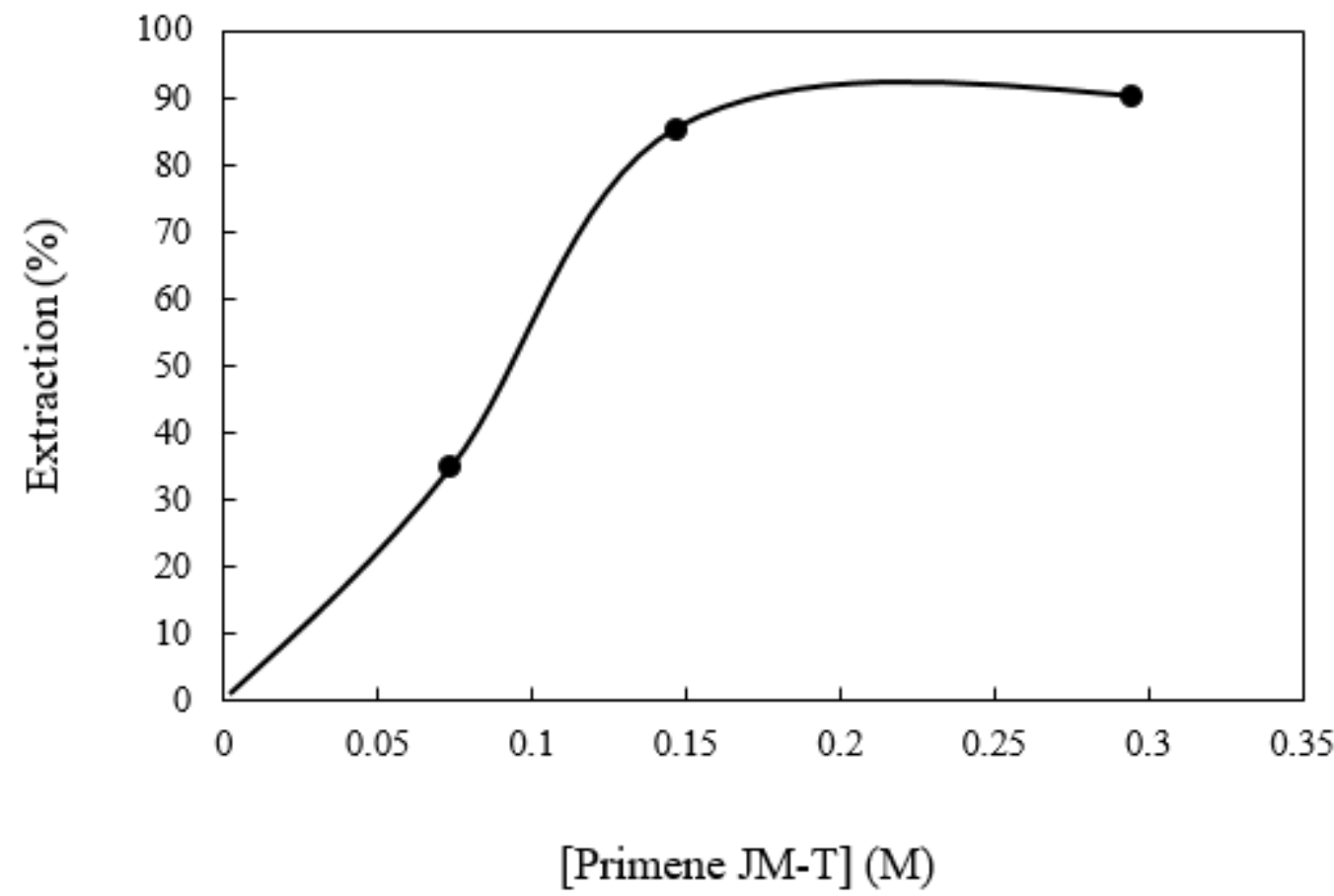

Figure 4.3: Percent extraction of yttrium as a function of Primene JM-T concentration.

The distribution coefficient, D, as a function of the Primene JM-T concentration plotted on a log-log scale gives information about the extraction mechanism that is taking place when yttrium is recovered from the copper PLS. This is Figure 4.4. As with the synthetic solution results presented in Chapter 3, the slope of this line is approximately 2 indicating that both $Y\left(\mathrm{SO}_{4}\right)_{2}^{-}$and $Y\left(\mathrm{SO}_{4}\right)_{3}^{3-}$ are being extracted. This indicates that the same mechanism is taking place with the PLS as was with the synthetic solution. 


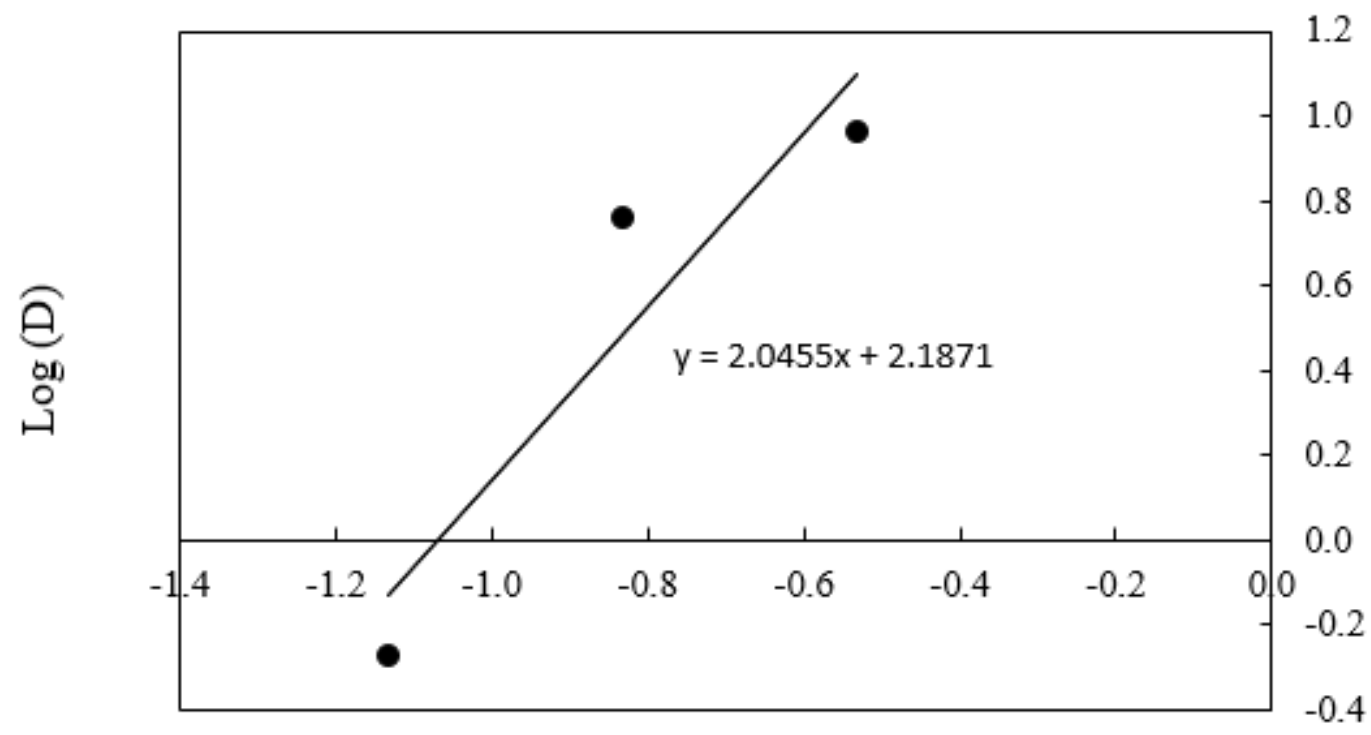

$\log ([$ Primene JM-T $])$

Figure 4.4: Distribution coefficient of yttrium as a function of Primene JM-T concentration using PLS.

The same effect of extractant concentration tests under the same conditions and with the same Primene JM-T concentrations were carried out for neodymium. The results are shown in Table 4.3. As with yttrium, no extraction of neodymium was achieved with the lowest, 0.0294 M, Primene JM-T concentration. Sixty-seven percent extraction was achieved with the $2.5 \% \mathrm{v} / \mathrm{v}$ extractant concentration while the 5\% and 10\% Primene JM-T resulted in 95\% extraction of neodymium. Figure 4.5 shows this extraction as a function of extractant concentration.

Table 4.3: Neodymium Effect of Extractant Concentration Using PLS

\begin{tabular}{|c|c|c|c|c|c|c|c|}
\hline & $\begin{array}{c}{[\text { Primene }} \\
\mathrm{JM}-\mathrm{T}](\mathrm{M})\end{array}$ & $\begin{array}{c}{[N d]} \\
(\mathrm{ppm})\end{array}$ & $\begin{array}{c}{[\overline{N d}]} \\
(\mathrm{ppm})\end{array}$ & $\mathrm{D}$ & $\log (\mathrm{D})$ & $\begin{array}{c}\log ([\text { Primene } \\
\mathrm{JM}-\mathrm{T}])\end{array}$ & $\begin{array}{c}\text { Extraction } \\
(\%)\end{array}$ \\
\hline $1 \%$ & 0.0294 & 2.1 & 0 & - & - & -1.532 & - \\
\hline $2.5 \%$ & 0.0735 & 0.7 & 1.4 & 2 & 0.301 & -1.134 & 67 \\
\hline $5 \%$ & 0.147 & 0.1 & 2 & 20 & 1.301 & -0.833 & 95 \\
\hline $10 \%$ & 0.294 & 0.1 & 2 & 20 & 1.301 & -0.532 & 95 \\
\hline
\end{tabular}




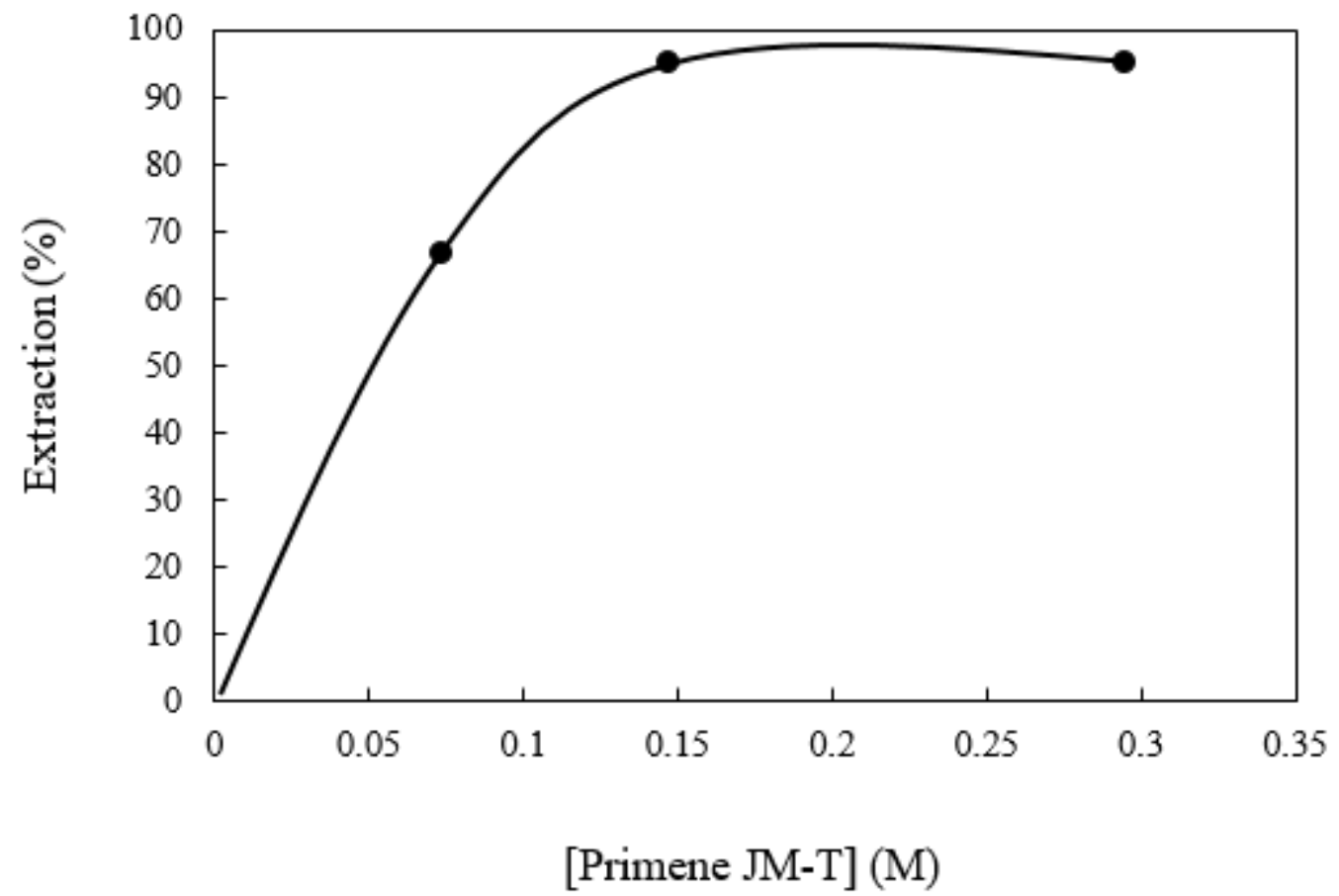

Figure 4.5: Percent extraction of neodymium as a function of Primene JM-T concentration.

As with yttrium, the distribution coefficient versus the Primene JM-T concentration for neodymium was plotted on a log-log scale (Figure 4.6). The slope was found to be approximately 1.7. This indicates that a mixture of two neodymium sulfate complexes are being extracted as well. These complexes are $\mathrm{Nd}\left(\mathrm{SO}_{4}\right)_{2}^{-}$and $\mathrm{Nd}\left(\mathrm{SO}_{4}\right)_{3}^{3-}$. 


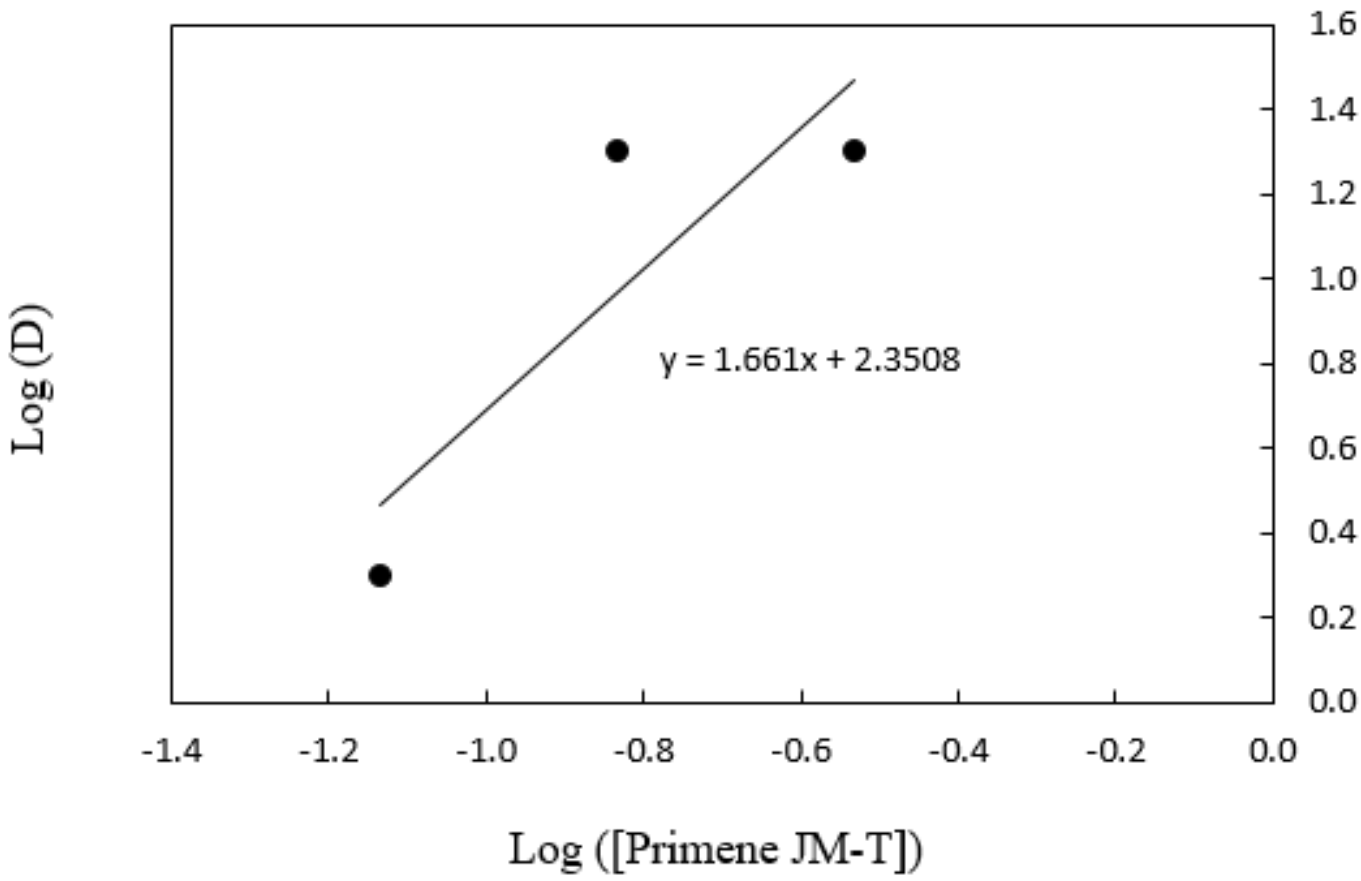

Figure 4.6: Distribution coefficient of neodymium as a function of Primene JM-T concentration using PLS. 


\section{CHAPTER 5: Conclusions and Future Work}

\subsection{Conclusions}

Primene JM-T, a primary amine, was found to successfully recover the rare earths, yttrium and neodymium, from synthetic solutions as well as from copper PLS. One major conclusion from this research dealt with the protonation of the organic. Utilizing organic that had not been protonated and the standard conditions of 5 minute contact time, $\mathrm{pH} \sim 2.5,10 \% \mathrm{v} / \mathrm{v}$ Primene JM-T concentration, and 1:1 O:A ratio $81 \%$ of yttrium and was extracted from the synthetic solution. It was found that protonating the organic before using it in extraction tests is critical. The extractant needed to be protonated to form an ammonia like molecule prior to being put in contact with the aqueous. Since the extraction of the desired metal occurs via an anionexchange between the extractant and the metal ions in the aqueous phase, the amine must be protonated in order to provide an anion for this reaction to occur. Additionally, in low $\mathrm{pH}$ systems, such as in this research, once the amine is protonated with sulfuric acid, it is in the bisulfate form. Using organic that had been protonated prior to the shake out test resulted in increased recovery; $99 \%$ extraction of yttrium was achieved when the organic was protonated and standard conditions were maintained.

Recovery of both yttrium and neodymium with Primene JM-T was successfully demonstrated from synthetic solutions. The extraction of yttrium and the extraction of neodymium proved to be very similar under standard conditions. The extraction of both rare earths happens very quickly. For both metals equilibrium was reached within 1 minute of contact time with the organic. By 5 minutes of contact time the reaction had definitely gone to completion and equilibrium had been reached. Studying the effect of the $\mathrm{pH}$ of the aqueous phase on the extraction determined that extraction of yttrium and neodymium is very poor at $\mathrm{pH}$ less than 1. Alternatively, extraction is nearly complete and independent of $\mathrm{pH}$ in the range of 1 to 3.5. PLS from operating copper mines usually has a $\mathrm{pH}$ in the range of $2-3$, so $\mathrm{pH}$ will not hinder the extraction of yttrium and neodymium from leach solutions. It was also found that extraction is independent of the sulfate concentration of the aqueous phase; the high sulfate content of some copper PLS will not deter extraction. Distribution isotherms were constructed for each metal which demonstrated that both metals could be extracted operationally in one 
stage. Studying the effects of these parameters on the extraction of yttrium and neodymium provided insight into the feasibility of recovering these metals from solution.

Additional tests were carried out with the yttrium synthetic solution to research the possibility of one batch of organic being able to continually extract yttrium from fresh aqueous feed upon multiple contacts. Since nearly complete extraction was achieved while studying all of the parameters previously mentioned, multiple contacts of the organic with fresh aqueous was tested under the conditions: 1:2 O:A ratio and 5\% v/v Primene JM-T concentration. It was found that the organic could continue to extract the desired metal for up to four contacts with fresh aqueous. Since the maximum capacity of the organic is never reached, multiple contacts of the same organic can be employed under certain conditions.

Varying the extractant concentration used in the extraction tests provided insight into the mechanism of the reaction and what yttrium species were actually being extracted. With sulfate concentration in the range of $0.3 \mathrm{M}$ to $1.3 \mathrm{M}$, as is common for copper PLS and was utilized in this research, it is possible for yttrium to complex with sulfate in the form of $Y\left(\mathrm{SO}_{4}\right)_{2}^{-}$or $Y\left(\mathrm{SO}_{4}\right)_{3}^{3-}$. Primene JM-T can extract both of these anionic species from solution. As the slope of the logarithmic plot of the distribution coefficient and the Primene JM-T concentration was 2, a mixture of both yttrium sulfate complexes was being extracted.

Recovery of yttrium and neodymium with Primene JM-T from PLS was also demonstrated. Yttrium and neodymium were successfully recovered from PLS containing approximately $15 \mathrm{ppm}$ yttrium and $2 \mathrm{ppm}$ neodymium. Varying the extractant concentration utilized to extract the rare earths from the PLS proved that the same yttrium sulfate complexes that were extracted from the synthetic solutions were also extracted from the PLS. The same reaction mechanism was occurring. Distribution isotherms constructed showed that yttrium and neodymium could both be extracted operationally from PLS in one stage. Extraction from PLS is feasible and occurs by the same mechanism as extraction from synthetic solutions.

\subsection{Future Work}

Future work could be carried out with both synthetic solutions and PLS in order to further understand the feasibility of extracting rare earths from solution. The area of contacting organic with fresh aqueous feed multiple times could benefit from further research. During this research 
it was found that using an O:A ratio of 1:2 and 5\% v/v Primene JM-T concentration the organic could continue to extract yttrium from up to four contacts with fresh feed, but when five and six contacts were tested, the organic and aqueous phases would not separate thus extraction could not be achieved. Additionally, another set of conditions (1:5 O:A ratio and 1\% v/v Primene JMT concentration) was tested, but at these condition no yttrium was recovered. In fact under these conditions, upon the second and consequent contacts with fresh aqueous feed, yttrium was actually kicked off of the extractant and returned to the aqueous phase. Further research should be done in this area in order to understand these results and determine the optimum conditions for reusing the same organic multiple times.

Additional knowledge about the mechanism of the extraction mechanisms taking place for the extraction of yttrium and neodymium from synthetic solutions and PLS could be obtained by performing more tests with varying the Primene JM-T concentration. Since 99\% extraction of neodymium was achieved at every extractant concentration tested, using smaller concentrations such as the $0.25 \%$ that was used for yttrium could result in a better understanding of the neodymium extraction mechanism. Further extractant concentration testing could also be beneficial with the PLS. The PLS was only tested with 1\%, 2.5\%, 5\%, and 10\% v/v Primene JMT concentration. As with neodymium, further understanding of the extraction mechanism could be obtained if smaller concentrations of extractant were tested.

Performing shake out tests with synthetic PLS that is made in the laboratory could greatly assist with understanding the extraction from PLS. As mentioned, PLS is comprised of many metals. Some of these metals, such as iron and aluminum, have the potential to form anionic complexes with sulfate. This would result in decreased rare earth recovery. Creating synthetic leach solutions in the laboratory would make it possible to determine which elements do in fact form anionic complexes with sulfate and thus hinder extraction. Knowing which elements negatively affect extraction would make it possible to predict if extraction of yttrium and neodymium from a specific PLS would be possible given the PLS' composition.

Once the extraction of yttrium and neodymium is fully understood the next step in determining how to operationally recover yttrium and neodymium from PLS would be to study the stripping of the desired metal off of the organic. This would be the next step in designing the process for recovering these rare earths by solvent extraction. 


\section{APPENDIX A}

$$
\begin{aligned}
& Y_{T}=\left[Y^{3+}\right]+\left[\mathrm{YSO}_{4}^{+}\right]+\left[Y\left(\mathrm{SO}_{4}\right)_{2}^{-}+\left[Y\left(\mathrm{SO}_{4}\right)_{3}^{3-}\right]\right. \\
& \mathrm{Y}^{3+}+\mathrm{SO}_{4}^{2-} \stackrel{\beta_{1}}{\rightarrow} \mathrm{YSO}_{4}^{+} \\
& \beta_{1}=\frac{\left[Y_{S O}^{+}\right]}{\left[Y^{3+}\right]\left[S O_{4}^{2-}\right]} \\
& {\left[\mathrm{YSO}_{4}^{+}\right]=\beta_{1}\left[\mathrm{Y}^{3+}\right]\left[\mathrm{SO}_{4}^{2-}\right]} \\
& \mathrm{Y}^{3+}+2 \mathrm{SO}_{4}^{2-} \stackrel{\beta_{2}}{\rightarrow} \mathrm{Y}\left(\mathrm{SO}_{4}\right)_{2}^{-} \\
& \beta_{2}=\frac{\left[Y\left(\mathrm{SO}_{4}\right)_{2}^{-}\right]}{\left[Y^{3+}\right]\left[\mathrm{SO}_{4}^{2-}\right]^{2}} \\
& {\left[Y\left(\mathrm{SO}_{4}\right)_{2}^{-}\right]=\beta_{2}\left[\mathrm{Y}^{3+}\right]\left[\mathrm{SO}_{4}^{2-}\right]^{2}} \\
& \mathrm{Y}^{3+}+3 \mathrm{SO}_{4}^{2-} \stackrel{\beta_{3}}{\rightarrow} Y\left(\mathrm{SO}_{4}\right)_{3}^{3-} \\
& \beta_{3}=\frac{\left[Y\left(\mathrm{SO}_{4}\right)_{3}^{3-}\right]}{\left[Y^{3+}\right]\left[\mathrm{SO}_{4}^{2-}\right]^{3}} \\
& {\left[Y\left(\mathrm{SO}_{4}\right)_{3}^{3-}\right]=\beta_{3}\left[Y^{3+}\right]\left[\mathrm{SO}_{4}^{2-}\right]^{3}} \\
& Y_{T}=\left[Y^{3+}\right]+\beta_{1}\left[Y^{3+}\right]\left[S O_{4}^{2-}\right]+\beta_{2}\left[Y^{3+}\right]\left[S O_{4}^{2-}\right]^{2}+\beta_{3}\left[Y^{3+}\right]\left[S O_{4}^{2-}\right]^{3} \\
& Y_{T}=\left[Y^{3+}\right]\left(1+\beta_{1}\left[S O_{4}^{2-}\right]+\beta_{2}\left[S O_{4}^{2-}\right]^{2}+\beta_{3}\left[S O_{4}^{2-}\right]^{3}\right) \\
& \frac{\left[Y^{3+}\right]}{Y_{T}}=\frac{1}{1+\beta_{1}\left[S O_{4}^{2-}\right]+\beta_{2}\left[S O_{4}^{2-}\right]^{2}+\beta_{3}\left[S O_{4}^{2-}\right]^{3}}
\end{aligned}
$$




\section{REFERENCES}

Anthony, Elizabeth Y., and Spencer R. Titley. "Progressive Mixing of Isotopic Reservoirs during Magma Genesis at the Sierrita Porphyry Copper Deposit, Arizona: Inverse Solutions." Geochimica El Cosmochimica Acta 52 (1988): 2235-249. Print.

Barton, Isabel. "REE Geochemistry in Copper Deposits." E-mail interview. 2 Dec. 2015.

Berber, J.S., Shaw, V.E., Rice, A.C., Lindstrom, R.E., and Bauer, D.J. Technology of bastnasite, Bureau of Mines Report of Investigations 5599, U.S. Department of the Interior, Washington, D.C., 1960.

Bryce, C., B. Waterman, and M. Shaw. "Pilot Plant Testing of a New Process for Rhenium Recovery from Copper PLS." Mining Engineering Sept. 2014: 60. Print.

Carvalho, R.G., and G.R. Choppin. "Lanthanide and Actinide Sulfate Complexes - I Determination of Stability Constants." Journal of Inorganic Nuclear Chemistry 29 (1967): 725-35. Print.

Carvalho, R.G., and G.R. Choppin. "Lanthanide and Actinide Sulfate Complexes - II Determination of Thermodynamic Parameters." Journal of Inorganic Nuclear Chemistry 29 (1967): 737-43. Print.

Coleman, C.F. "Amines as Extractants." Nuclear Science and Engineering 17.2 (1963): 27486. Print.

Crouse, D.J., and J.O. Denis. "The Use of Amines as Extractants for Thorium (and Uranium) from Sulfuric Acid Digests of Monazite Sands." (1955). Print. 
Desouky, O.A., A.M. Daher, Y.K. Abdel-Monem, and A.A. Galhoum. "Liquid-Liquid Extraction of Yttrium Using Primene-JMT from Acidic Sulfate Solutions." Hydrometallurgy 96 (2009): 313-17. Print.

El-Yamani, I.S., and E.I. Shabana. "Solvent Extraction of Lanthanum (III) from Sulphuric Acid Solutions by Primene JMT." Journal of the Less-Common Metals 105 (1985): 25561. Print.

Emsley, John. "Neodymium." Periodic Table. Royal Society of Chemistry, 2014. Web. <http://www.rsc.org/periodic-table/element/60/neodymium〉.

Emsley, John. "Yttrium." Periodic Table. Royal Society of Chemistry, 2014. Web. $\langle$ http://www.rsc.org/periodic-table/element/39/yttrium>.

Gambogi, Joseph. "USGS Mineral Commodity Summary 2015." U.S. Department of the Interior, 2015. Print.

George, D'Arcy R., J. Richard Ross, and John D. Prater. "Recovery of Uranium from Copper Waste Dump Leaching Solution." Bureau of Mines, U.S. Department of the Interior, Salt Lake City Metallurgy Research Center, 1967.

Gupta, C.K., and N. Krishnamurthy. Extractive Metallurgy of Rare Earths. Boca Raton: CRC, 2005. Print.

Gupta, C.K., and T.K. Mukherjee. Hydrometallurgy in Extraction Processes. Vol. 1. Boca Raton: CRC, 1990. Print.

Habashi, Fathi. "A Short History of Hydrometallurgy." Hydrometallurgy 79 (2005): 15-22. Print.

Habashi, Fathi. "Extractive Metallurgy of Rare Earths." Canadian Metallurgical Quarterly 52.3 (2013). Print. 
Ichikawa, Fujio. "A Study on Anion Exchange and Amine Extraction of Rare Earth Elements in Nitric Acid." Bulletin of the Chemical Society of Japan 34.2 (1961): 183-86. Print.

Kaczmarek, J. Discovery and commercial separations. In Gschneidner, Jr., K.A. (ed.), Industrial Applications of Rare Earth Elements, ACS Symp. Ser. 164, American Chemical Soc., Washington D.C. (1981): 135-166. Print.

Kawamura, Kazutaka, and T. Takeuchi. "Extraction of Trivalent Rare Earths and Tetravalent Cerium by the Amex Method." Kinzoku Zairyo Gijutsu Kenkyusho Kenkyu Hokoku 6.5 (1963): 329-36. Print.

Lang, James R., and Spencer R. Titley. "Isotopic and Geochemical Characteristics of Laramide Magmatic Systems in Arizona and Implications for the Genesis of Porphyry Copper Deposits." Economic Geology 93 (1998): 138-70. Print.

Leddicotte, G.W., and F.L. Moore. "A New Solvent Extraction Method for the Separation of Niobium and Tantalum." Journal of the American Chemical Society (1952): 1618.

Levenson, Yvonne, Sole, and Hiskey. "Yttrium Behavior in Amine Solvent Extraction." (1992).

Marston, Charles R., and Christopher R. Eicher. Nickel and Cobalt Recovery Using Continuous Ion Exchange. Dow Global Technologies Llc, assignee. Patent US9068247 B2. 30 June 2015. Print.

McGill, I. Rare earth elements. In Elvers, B., Hawkins, S., Russy, W., and Schulz, G. (eds.), Ullman's Encyclopedia of Industrial Chemistry, Vol., A22, (1993): 607-649, $\mathrm{VCH}$, Weinheim.

"Mineral Prices." MineralPrices.com. 16 Nov. 2015. Web. <http://mineralprices.com/>. 
"Molycorp To Move Its Mountain Pass Rare Earth Facility To 'Care and Maintenance’ Mode." MCP News Releases. Molycorp, 26 Aug. 2015. Web.

<http://www.molycorp.com/molycorp-to-move-its-mountain-pass-rare-earth-facility-tocare-and-maintenance-mode/>.

Nebeker, Neil, Matthew L. Rodgers, and Charles R. Marston. Methods for Recovering Cobalt from Copper Solvent Extraction Raffinate. Asarco Llc, assignee. Patent US8658114 B2. 25 Feb. 2014. Print.

Nebeker, Neil. Rhenium Recovery. Asarco Llc, assignee. Patent US20120152063 A1. 21 June 2012. Print.

Nekovar, P., and D. Schrotterova. "Extraction of V(V), Mo(VI) and W(VI) Polynuclear Species by Primene JMT." Chemical Engineering Journal 79 (2000): 229-33.

Nekovar, P., D. Schrotterova, and M. Mrnka. "Extraction of Metal Ions with a Primary Amine." Journal of Radioanalytical and Nuclear Chemistry 223.1-2 (1997): 17-22.

"Primene JM-T Amine." Dow. Rohm and Haas, Web. <http://www.dow.com/assets/attachments/business/process_chemicals/primene_amines/p rimene_jm-t/tds/primene_jm-t.pdf>.

"Primene JM-T." Pub Chem. National Center for Biotechnology Information, 8 Aug. 2005. Web. <http://pubchem.ncbi.nlm.nih.gov/compound/111882\#section=Top>.

Rezkallah, Areski. Method for the Recovery of Uranium from Pregnant Liquor Solutions. Rohm And Haas Company, assignee. Patent US8864872 B2. 21 Oct. 2014. Print.

Rice, A.C., and C.A. Stone. Amines in Liquid-Liquid Extraction of Rare-Earth Elements, Bureau of Mines Report of Investigations 5923, U.S. Department of the Interior, Washington, D.C., 1962. Print. 
Rice, Andrew C. Process for Separating the Rare Earth Elements by Means of Solvent Extraction. Rice, Andrew C., assignee. Patent US21600562A. 29 June 1965. Print.

Ritcey, G.M., and A.W. Ashbrook. Solvent Extraction: Principles and Applications to Process Metallurgy. Vol. 1. Amsterdam: Elsevier Science B.V., 1984. Print.

Ritcey, G., and B. Lucas. Co-Extraction and Separate Recovery of Uranium and Thorium from Acid Solutions. Canadian Patents and Development Limited, assignee. Patent US3835213 A. 10 Sept. 1974. Print.

Shaw, V.E. Extraction of yttrium and rare earth elements from Arizona euxenite concentrate, Bureau of Mines Report of Investigations 5544, U.S. Department of the Interior, Washington, D.C., 1959. Print.

Sillen, Lars Gunnar, and Arthur E Martell. Stability Constants of Metal-Ion Complexes. London: Chemical Society, Burlington House, 1964. Print.

Udayar, T., M.H. Kotze, and V. Yahorava. Recovery of Uranium from Dense Slurries via ResinIn-Pulp. Proc. of 6th Southern African Base Metals Conference 2011, The Southern African Institute of Mining and Metallurgy. N.p.: n.p., 2011. 49-64. Print.

Wagman, Donald D., William H. Evans, Vivian B. Parker, Richard H. Schumm, Iva Halow, Sylvia M. Bailey, Kenneth L. Churney, and Ralph L. Nuttall. "The NBS Tables of Chemical Thermodynamic Properties." Journal of Physical and Chemical Reference Data (1982). Print.

World Mining (1966) Molycorp uses solvent extraction to separate europium oxide from rare earths, World Mining 2(3): 16-19. 